\title{
Experimental approaches to the development of use-wear traces on volcanic rocks: basalts
}

\author{
Patricia Bello-Alonso ${ }^{1,2}$ - Joseba Rios-Garaizar ${ }^{1}$. Joaquín Panera ${ }^{1,2}$ • David Manuel Martín-Perea ${ }^{2,3,4}$. \\ Susana Rubio-Jara ${ }^{1,2}$ - Alfredo Pérez-González ${ }^{2,5}$ • Raquel Rojas-Mendoza ${ }^{2,5}$ - Manuel Domínguez-Rodrigo ${ }^{2,6}$. \\ Enrique Baquedano ${ }^{2,7}$. Manuel Santonja ${ }^{1,2,5}$
}

Received: 27 November 2019 / Accepted: 31 March 2020

(C) Springer-Verlag GmbH Germany, part of Springer Nature 2020

\begin{abstract}
In this paper we present the experimental results obtained for the formation of use-wear traces on four types of basalt rocks from the Olduvai Gorge (Tanzania) and one from the Deba River (Spain). The objective of this study is to create a reference collection that will allow the posterior analysis and identification of archeological use-wear traces on lithic industries made on these different types of basalt, such as the Acheulean lithic industry from Thiongo Korongo site (TK) (Olduvai's Bed II, ca. 1.353 $\pm 0.035 \mathrm{Ma}$.). This study includes five types of basalt, under the objective of understanding in more detail the formation of the use-wear traces. Additionally, we include their individual petrographic, chemical, and traceological interpretations, allowing for an assessment of the intrinsic characteristics in relation to the development of use-wear. The final step of this process includes microscopic analysis for the detailed characterization and description of these use-wear traces. The results obtained reveal the internal structure of basalts as a significant conditioning factor in the development of use-wear traces. Despite this, we have been able to establish several criteria that discriminate between actions and different worked materials. These results offer a fundamental experimental basis for the future interpretation of use-wear traces found in archeological basalts.
\end{abstract}

Keywords Use-wear $\cdot$ Reference collection $\cdot$ Basalts $\cdot$ Olduvai Gorge

Electronic supplementary material The online version of this article (https://doi.org/10.1007/s12520-020-01058-6) contains supplementary material, which is available to authorized users.

Patricia Bello-Alonso

patriciamariabelloalonso@gmail.com

1 Centro Nacional de Investigaciones sobre la Evolución Humana, Paseo Sierra de Atapuerca no. 3, 09002 Burgos, Spain

2 Instituto de Evolución en África, Covarrubias 36, 28010 Madrid, Spain

3 Palaeobiology Department, National Natural Sciences Museum CSIC, José Gutiérrez Abascal 2, 28006 Madrid, Spain

4 Geodynamics, Stratigraphy and Palaeontology Department, School of Geological Sciences, Complutense University of Madrid, José Antonio Novais 12, 29040 Madrid, Spain

5 Asociación Nacional El Hombre y el Medio, 28982 Madrid, Spain

6 Departamento de Historia y Filosofia, Universidad de Alcalá de Henares, 28040 Madrid, Spain

7 Museo Arqueológico Regional, Plaza de las Bernardas s/n, 28801 Alcala de Henares, Spain

\section{Introduction}

The creation of reference collections is essential for the analysis and interpretation of the function of archeological materials through use-wear analysis. Nevertheless, it is still of great importance to pay particular attention to the experimental protocols used in order to improve our interpretative discourse. In the case of basalts, considering their variability in terms of internal structure and mineralogical composition, the incorporation of a wide range of basalt types is essential, allowing for a better understanding of how their internal proprieties may influence use-wear development. For this reason, we have also considered relevant the incorporation of other types of basalt (Deba River) in comparison with Olduvai basalts, providing a broader perspective for the formation of use-wear traces. Use-wear analysis of basalt artifacts has been a topic of interest attracting attention since the 1970s (Price-Beggerly 1976; Stanfford 1977; Kamminga 1978; Montgomery 1978; Odell 1980; Plisson 1982, 1985; Schutt 1982; Richards 1988; Grace 1989; Deunert 1995; Rodríguez Rodríguez 1998; Álvarez et al. 2001; Dubreuil 2004; Asryan et al. 2014; de Francisco 2015; Stemp et al. 2015). These studies present well-known experimental protocols 
including different petrological varieties of basalt (in terms of internal structure and chemical composition). From these petrological results, it has been possible to obtain some common criteria for the identification of use-wear traces in basalt. Nevertheless, these use-wear traces are highly dependent on the precise nature of the basalt being used (Richards 1988).

Recent studies have summarized the nature of use-wear traces on materials from the Olduvai Gorge, focusing on experimental and archeological lithic materials elaborated with Naibor Soit quartzite (NQ) (Sussman 1987; de la Torre et al. 2013; Arroyo and de la Torre 2016 and 2018; Arroyo et al. 2016; Benito-Calvo et al. 2018; Bello-Alonso et al. 2019). While NQ is the most representative raw material in the Acheulean record in this area, basalt also represents an important source of raw material in the production of tools in these sites (Leakey 1971; de la Torre and Mora 2005 and 2014; Díez-Martín et al. 2015; Santonja et al. 2014, 2018; Rubio-Jara et al. 2017). To date, only a preliminary study has incorporated basalt from Olduvai Gorge outcrops in their experimental protocols, presenting some results regarding the formation of macro-traces, polishes, and striations (de Francisco 2015).

All these previous efforts are a great source of information, nevertheless precise information on the nature of use-wear formation on Olduvai basalts is needed to sustain posterior analyses of archeological artifacts. Moreover, our hypotheses of a wide economic activity by the Acheulean hominins in this area demands the incorporation of new worked materials into our experimental reference samples. Following the approach that has already been proposed for the analysis of NQ (Bello-Alonso et al. 2019), the present study also incorporates a broad range of tasks experimenting with the processing of plant resources (underground storage organs -USOs-, wood, herbaceous plants -grass and canes-, and animal carcasses -butchering and bone-).

The variety of basalts used in this study have allowed for the detection of modifications in use-wear formation related to the internal structure and components of the raw materials. In accordance with these finds, the present work documents the parallelisms and differences between different basalts and in relation with other studies on this raw material. The results obtained present interesting data that supports the need for experimental protocols of this nature. For this reason, we have combined description of the petrographic characterization of these raw materials alongside their corresponding use-wear data, supported by a detailed micro-photographic compilation for future reference.

\section{Materials and methods}

\section{Basalt reference collection}

For the purpose of this study, five basalt samples were used using the development of use-wear traces as an analytical approximation: BTD (Fig. 1a), BT1 (Fig. 1b), BT2 (Fig. 1c), BT4 (Fig. 1d), and BT5 (Fig. 1e). BTD samples were collected on the margin of the Deba River (Basque Country, Spain) by J. Rios-Garaizar, while the rest of basalt varieties were collected on the margin of the Olduvai River (Olduvai Gorge, Tanzania) by D.M. Martín-Perea and P. Bello-Alonso (Fig. S1a). Apart from the experimental protocol and traceological analysis, thin sections of each of these samples were petrographically and mineralogically studied (X-ray diffraction -DRXand X-ray fluorescence spectrometry -FRX- analyses were carried out on all samples). The main objectives of this petrographic analysis are (a) technical characterization of the different varieties of basalt, including the verification of their typology (avoiding visu mistakes due to the wide range of volcanic rocks and their similarities) and (b) to identify the structural characteristics that could condition the formation of use-wear patterns (Hay 1976; Richards 1988; Pedergnana et al. 2017; McHenry and de la Torre 2018).

\section{Use-wear attributes on basalts}

The attributes used for the description of use-wear traces follow the same criteria as those use by Bello-Alonso et al. (2019), thus applying common parameters in research established throughout the last couple of decades (Tringham et al. 1974; Odell 1975, 1980; Cotterell and Kamminga 1979; Kamminga 1979; Keeley 1980; Mansur-Franchomme 1983; Plisson 1985; Fullagar 1986; Knutsson 1988a, 1988b; Richards 1988; Sussman 1988; Estévez and Urquijo 1996; Clemente and Gibaja 2009).

These attributes include information about the location, morphology, distribution, and termination of macro- and micro-scars that can be useful for determining the relative hardness of the worked materials and gestures used throughout each activity (Tringham et al. 1974; Cotterell and Kamminga 1979; Odell 1980; Richards 1988; Estévez and Urquijo 1996). Micro-wear analyses (50× to 400× magnifications) further focus on traces including polish, striations, and pits. For the description of polish diagnostic criteria, we used the polish formation, extension, abrasion, relative brightness, and lineal components (Keeley 1980; Vaughan 1981; Mansur Franchomme 1983; Plisson 1985; Knutsson 1988a, 1988b; Sussman 1988; Fullagar 1986; Grace 1989; Estévez and Urquijo 1996; Márquez et al. 2016; Bello-Alonso et al. 2019). We also documented the formation of edge rounding (low, moderate, high), considering this variable as an indicator of use (Richards 1988). Pits and striations are also linked to the formation of polishes, and both were analyzed and described according to their corresponding characteristics (Keeley 1980; Mansur Franchomme 1982; Knutsson 1988a; Richards 1988; Grace 1989; Estévez and Urquijo 1996; Bello- 
$\mathbf{a}$

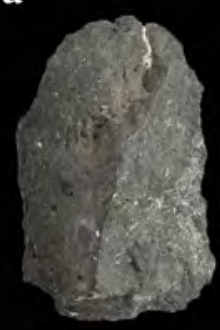

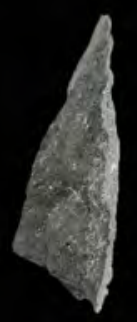

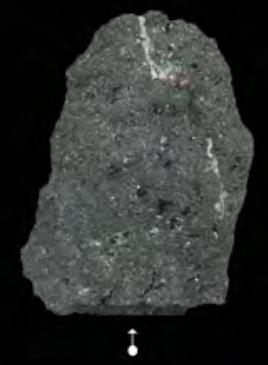

b
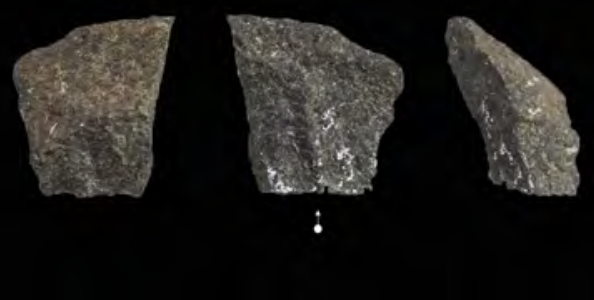

c

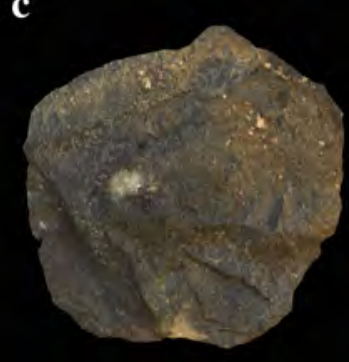

d
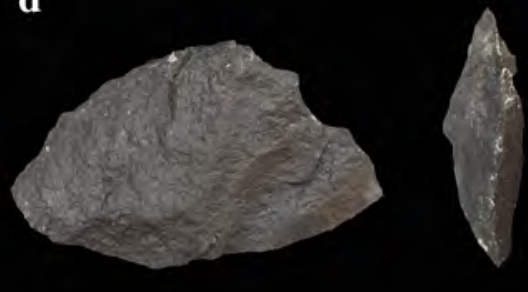

e

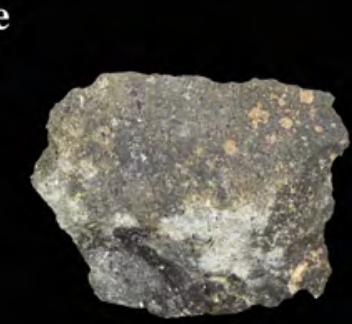

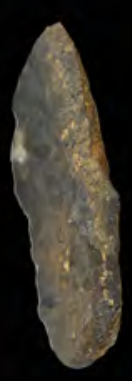
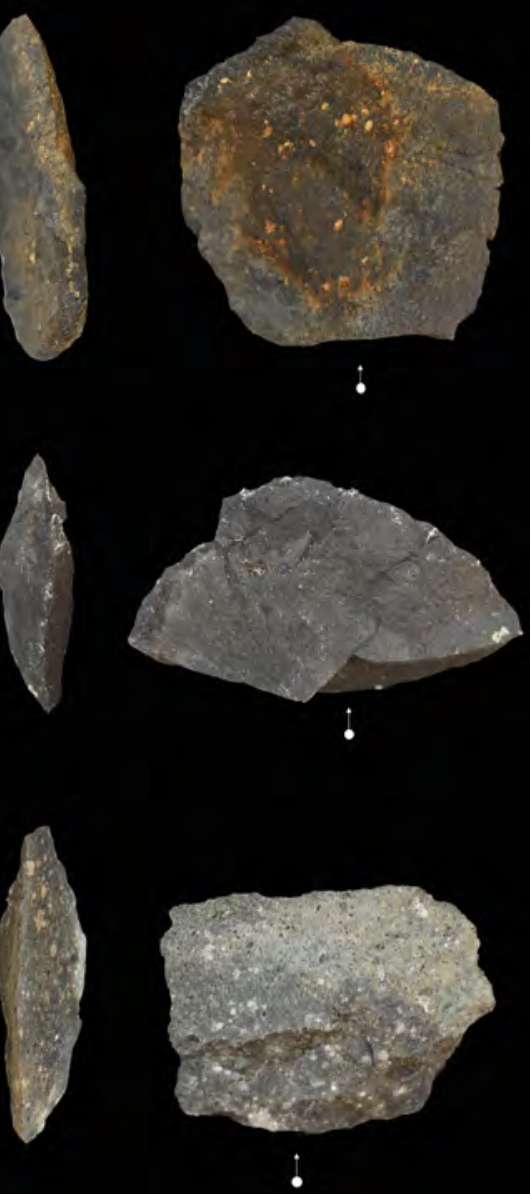

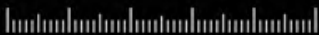

CET / QCENIEH / labsecenieh.es

Fig. 1 Types of basalts processed during each experiment: a basalt type Deba (BTD); b basalt type 1 (BT1); c basalt type 2 (BT2); d basalt type 4 (BT4);e basalt type 5 (BT5)

Alonso et al. 2019). In the case of striations, their location, orientation (oblique, parallel, and right angle), frequency, and length were considered. Furthermore, in the case of pits, descriptions included their relative abundance, size, and orientation. Finally, differentiation between common and comettailed pits were included (Keeley 1980; Sussman 1988).

\section{Reference CET}

All the experimental pieces and corresponding traceological information have been incorporated in the experimental collection of traceology (CET) collection, currently stored in the Prehistory Technology and Archaeology Laboratory in the 
Centro Nacional de Investigación sobre la Evolución Humana (CENIEH) (Burgos, Spain). Experiments were carried out in the Prehistory Technology and Archaeology Laboratory (CENIEH, Burgos, Spain), the Valdivielso valley (Burgos, Spain), and at the Emiliano Aguirre station (Olduvai Gorge, Tanzania) by P. Bello-Alonso. Butchering experiments were performed on goats with the participation of Masai residents of the Olduvai Gorge's surrounding areas, all of them expert butchers.

Following the protocols established in previous studies (Bello-Alonso et al. 2019), the development of each activity was focused on the processing of different types of wood, animal carcasses, and underground storage organs (USOs) (Fig. S2a, S2b, S2c, and S2d). Each activity was performed for a duration of 15,30 , or $60 \mathrm{~min}$ (Table 1). Within the USO samples, a new species was also incorporated within the study, Vigna sp. (Schnorr et al. 2015). This plant is a legume that develops edible roots, growing in certain areas along the Olduvai Gorge. This legume is currently consumed by Masai populations, especially by children. This particular potato is not cooked, yet Masai are observed to peel it, chop it up, and suck on it in order to obtain its fluids (field observations). The selection of activities and materials worked were made attempting to provide an analogy to data observed in the archeological record (Keeley and Toth 1981; Keeley 1997; Domínguez-Rodrigo et al. 2001; Lemorini et al. 2014, 2019; Yravedra et al. 2016, 2017), early hominid dietary studies (Ungar et al. 2006), and ethnographic reports (Marlowe and Berbesque 2009; Pontzer et al. 2012).

\section{Cleaning}

The cleaning of each experimental piece was performed using neutral soap (Derquim LM02-Teepol) and demineralized water. Some pieces were cleaned using an ultrasonic tank (Branson 3510) with demineralized water and acetic acid dissolution $(3 \%)$ for a period of 5 to $25 \mathrm{~min}$. The use of an ultrasonic tank in this case study proved problematic due to the production of residue composed of small basalt fragments. This loss of material can come from the edge as well as other parts of the flake. Despite this, at a macroscopic level, we are yet to observe any major modification on these particular edges (Table 1). For this reason, we opted for cleaning the pieces with neutral soap, alcohol, and cotton swabs, following the same procedure proposed by Bello-Alonso et al. (2019) for Naibor Soit Quartzite.

\section{Techniques}

Experimental tools were examined at low power magnifications $(0.7 \times$ to $11.5 \times)$ using an Olympus SZX16 binocular microscope, and high-power magnifications $(50 \times$ to $400 \times)$ were performed using an Olympus BX51 metallographic microscope coupled with Differential Interference Contrast (DIC) prism. Photographs were taken with a Nikon camera (DS-8Fi2) and using the NIS-Elements D 4.13.04 software. A series of multiple focus images were also obtained with this software as well as multifocus reconstructions using the Helicon Focus 6 software.

\section{Results}

\section{Petrographic analysis}

Assessment of inter-basalt variability through petrographic analyses was performed under the premise of evaluating the traceological differences presented by the raw materials according to their mineralogical and internal composition. These petrographic descriptions revel that BT1 (Fig. 2a) contains acicular, elongated plagioclase crystals $(<0.4 \mathrm{~mm})$ alongside smaller and much less abundant pyroxene and hornblende crystals in a fine-grained feldspathic groundmass with disperse mica patches (Table S1 and Table S2); BT2 (Fig. 2b) and BT5 (Fig. 2c) show well-defined, prismatic 0.2-0.8 mm crystals of nepheline, feldspar, and pyroxene embedded in a very fine-grained matrix (Table S1 and Table S2); BT4 (Fig. $2 \mathrm{~d})$ is mainly composed of a feldspar microlite groundmass with hyalopilitic texture with few larger $(<0.1 \mathrm{~mm})$ pyroxene and feldspar crystals (Table S1 and Table S2); and BTD shows scarce large chlorite crystals $(<0.5 \mathrm{~mm})$ in a finegrained plagioclase groundmass (Fig. 2e) (Table S1 and Table S2).

\section{Use}

\section{Herbaceous plants}

Cutting grass (Lolium perenne): to cut Lolium perenne, one tool was used for a total of $30 \mathrm{~min}$ (EXP109/BT1). Scars are poorly developed presenting a bifacial distribution (Table 2). The most common scar morphologies observed are half-moon and semicircular, appearing isolated and without overlapping. Terminations present a clear tendency towards snap and step types with few feather terminations. Micro-scarring is scarce, while no observations have been observed in association with any other traces; these present an isolated distribution without overlapping and half-moon and semicircular morphologies.

In terms of micro-analysis (Table 3), well developed polishes have been identified in patches (Fig. 3a) with undulating and smooth surfaces. These polishes are well developed in the higher areas of the microtopography and in the more exposed areas of the edge. The polish is bright for undulating polish and very bright for smooth polish (Fig. 3b). Lineal components are also present (Fig. 3c), appearing short and parallel to the edge, following the direction of the activity's working 


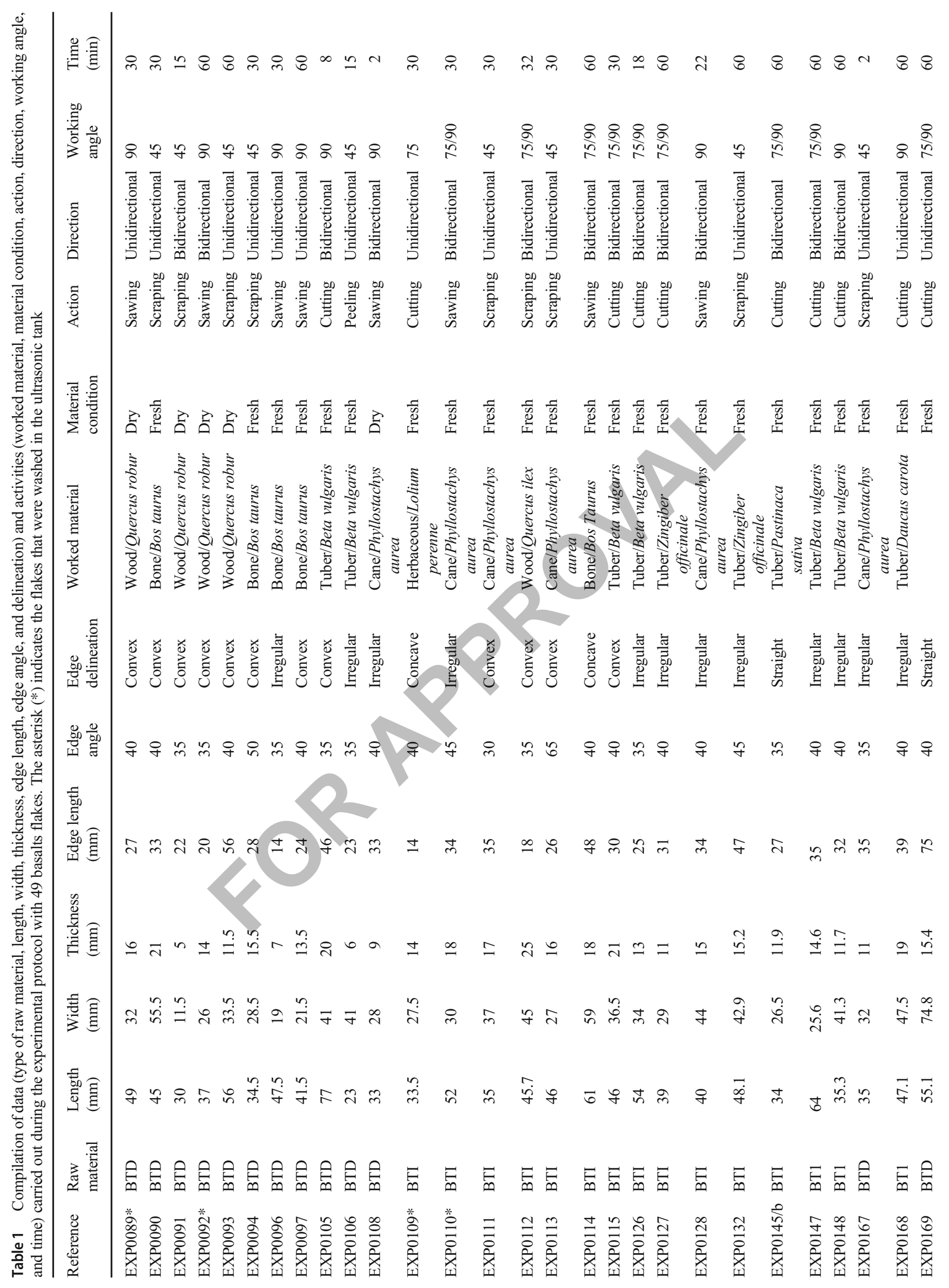


导 含

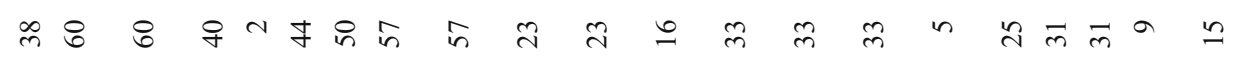

辛

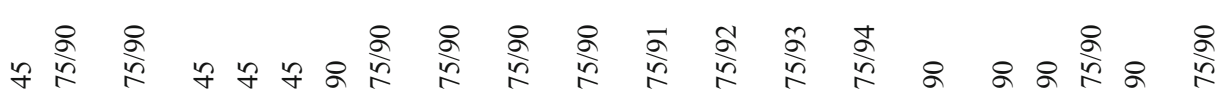

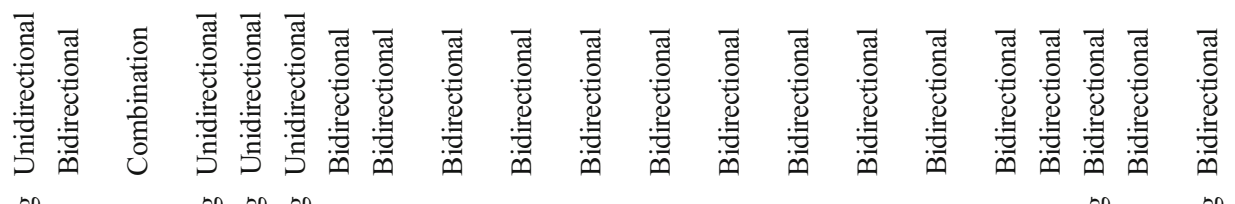

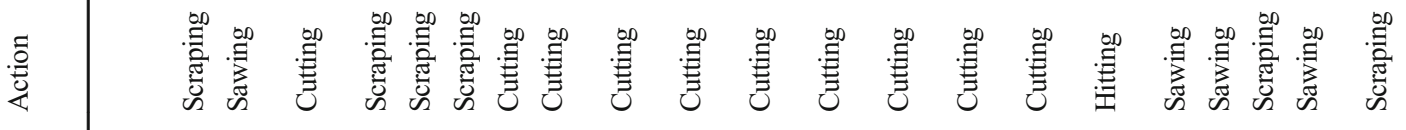

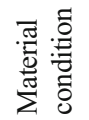

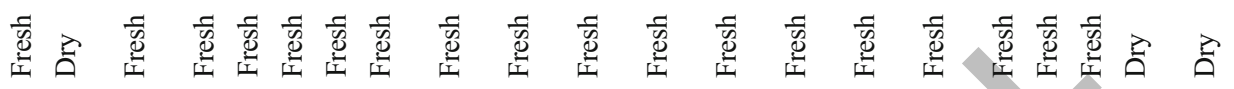

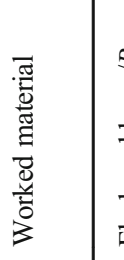

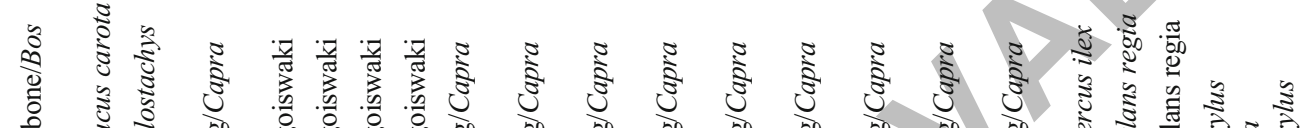

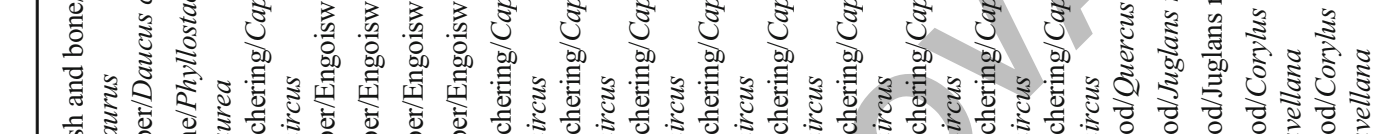

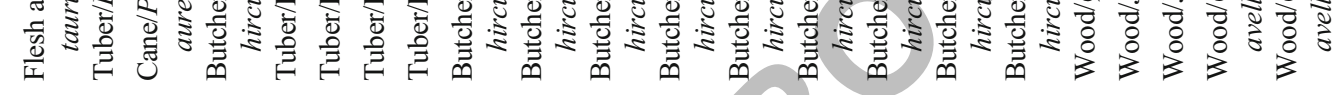

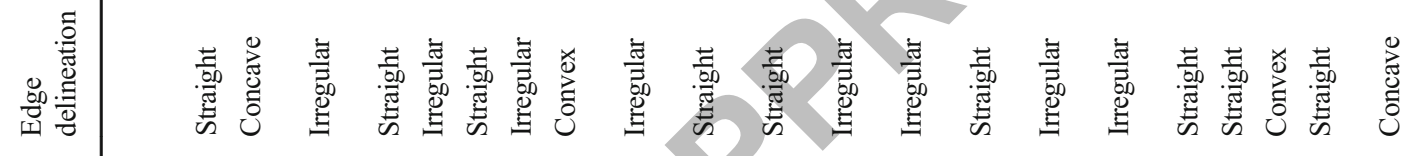

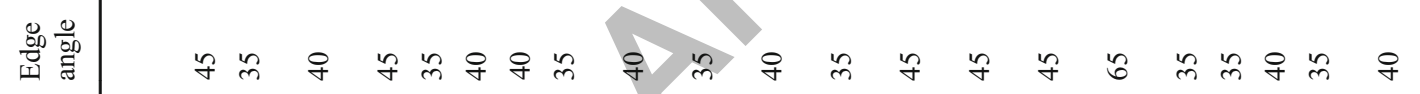
홍 สิส ปิ

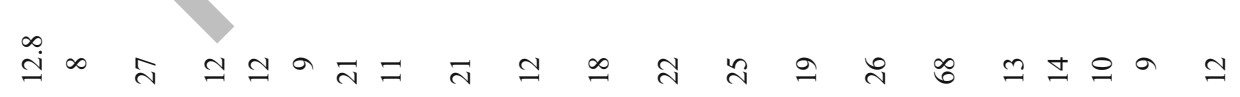

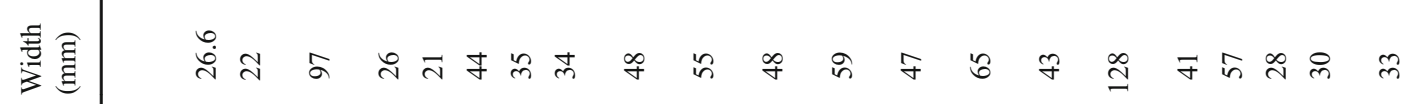

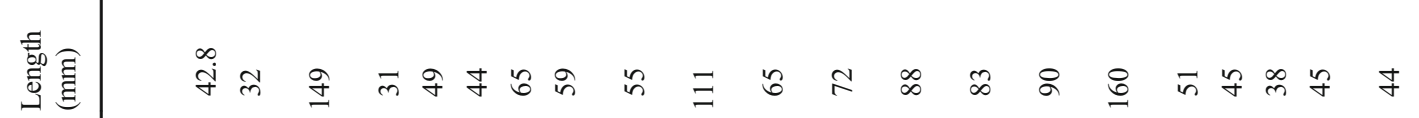

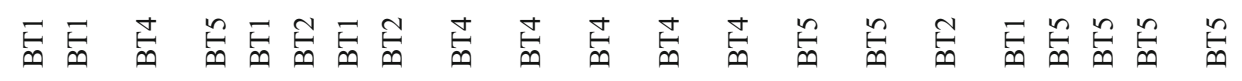

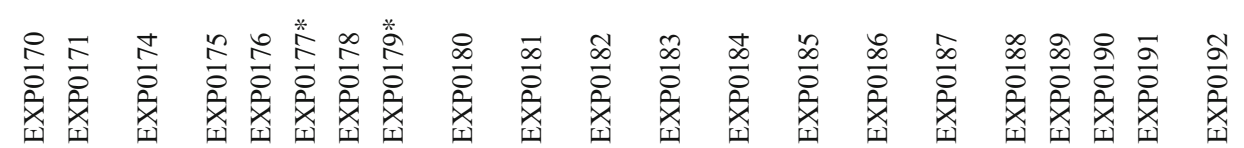


Fig. 2 Petrographic analysis of basalts: a well-defined plagioclase $(\mathrm{Pl})$ crystals $(<0.4 \mathrm{~mm}$ elongate axis, $50 \%$ ), pyroxene (Py) crystals (high interference colors, $<30 \%$ ), and amphibole (Am) crystals (mostly hornblende, $10 \%$ ) in a fine-grained feldspathic groundmass (10\%) with disperse mica patches. XPL image, $2 \times$ (field of view $=2 \mathrm{~mm}$ ); b nepheline $(\mathrm{Ne})$ crystals $(<$ $0.3 \mathrm{~mm},<20 \%$ ), feldspar (F) crystals $(<10 \%)$, and pyroxene (Py) crystals (high interference colors, $<15 \%$ ) in a very finegrained groundmass $(>70 \%)$. XPL image, $2 \times$ (field of view $=$ $2 \mathrm{~mm}$ ); c nepheline (Ne) crystals $(<0.8 \mathrm{~mm},<30 \%)$, feldspar $(\mathrm{F})$ crystals $(<10 \%)$, and pyroxene (Py) crystals (high interference colors, $<10 \%$ ) in a very finegrained groundmass $(>60 \%)$. XPL image, $2 \times$ (field of view $=$ $2 \mathrm{~mm}$ ); d pyroxene crystals (high interference colors, $<0.1 \mathrm{~mm}$, < $20 \%)$ in a feldspar (>80\%) microlite groundmass with hyalopilitic texture. XPL image, $2 \times$ (field of view $=2 \mathrm{~mm}$ ); chlorite crystals $(<0.5 \mathrm{~mm} ; 10 \%)$ in a fine-grained plagioclase groundmass ( $>80 \%)$. Other phyllosilicates such as smectite are present $(<5 \%)$. Some magnetite crystals $(<0.1 \mathrm{~mm})$ can be observed (5\%). XPL image, $2 \times$ (field of view $=2 \mathrm{~mm}$ )

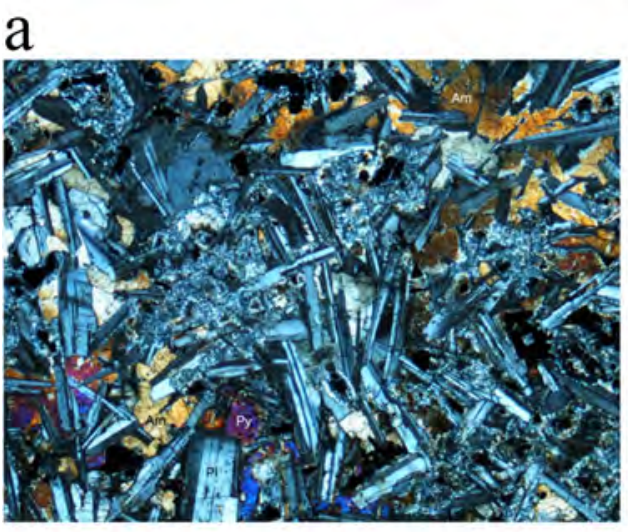

b

c
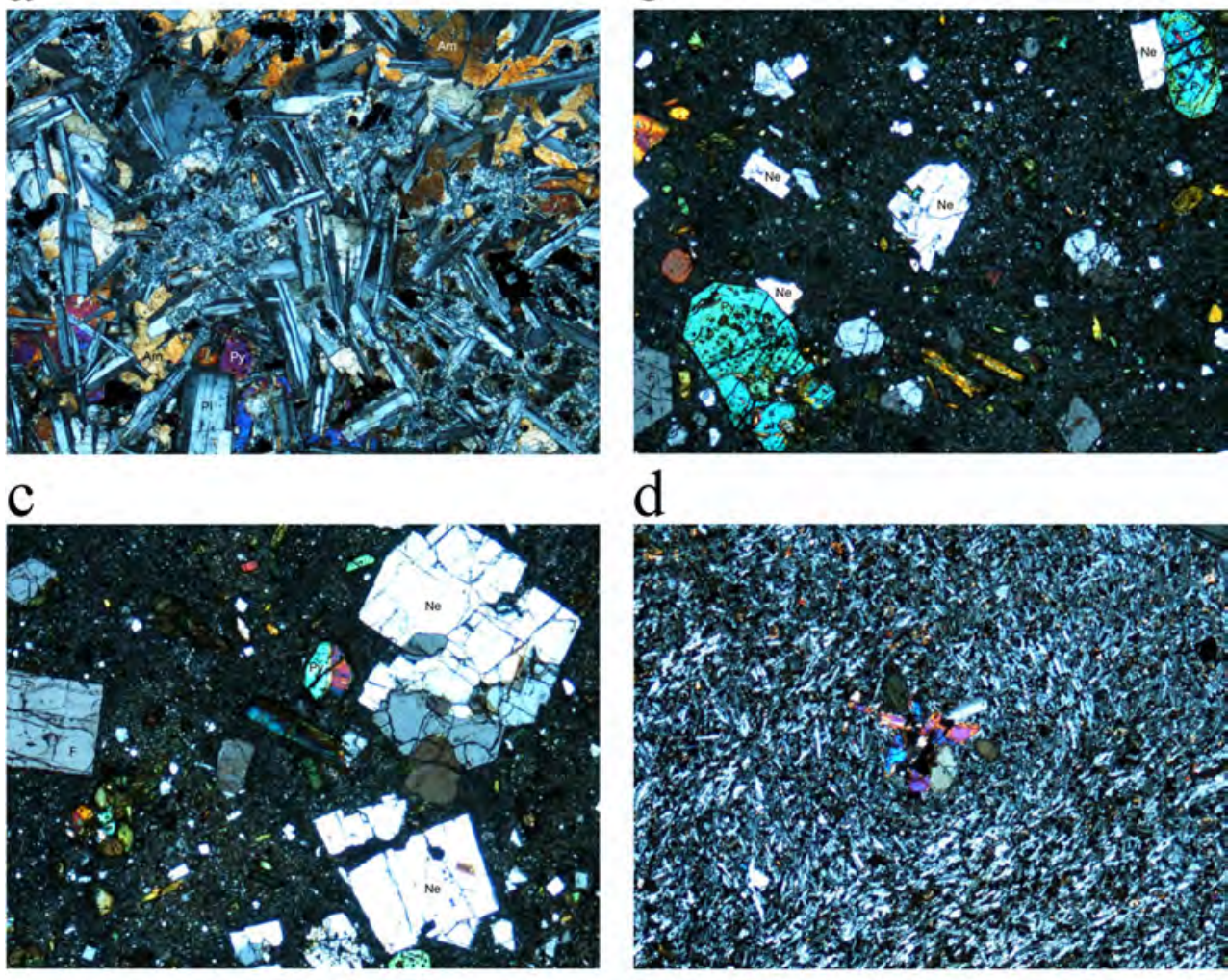

d

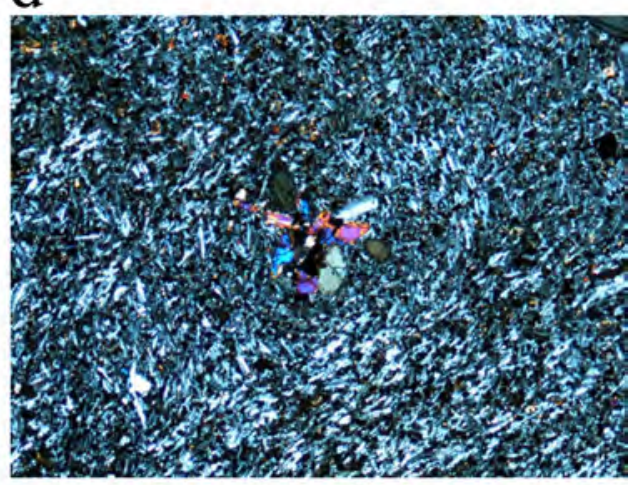

e

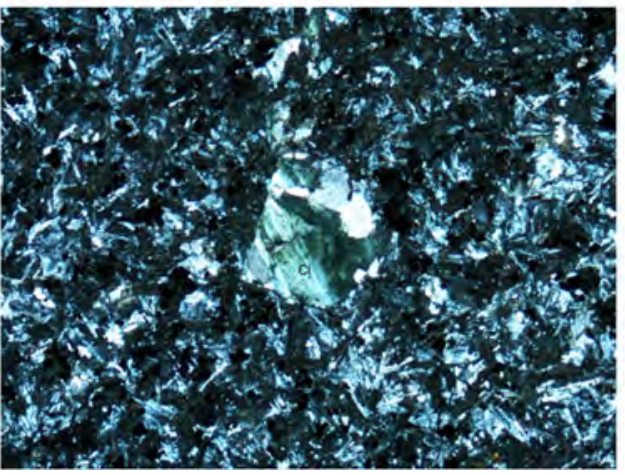

movement. Other features such as edge rounding or pits are almost absent, even though previous studies have attributed the formation of pits as common in association with plant processing (Richards 1988). Only few rounded areas have been observed with a moderate development (Fig. 3d) (Table 3).

\section{Canes}

Scraping fresh cane (Phyllostachys aurea): for this activity, we used three flakes for a time period between 2 and $30 \mathrm{~min}$ (EXP111/BT1; EXP113/BT1, and EXP/BTD). Data collected were obtained from results with $\mathrm{BT} 1$, considering how the BTD flake did not generate significant information. The location of scars is unifacial, and the most common morphologies are half-moon and semicircular (Table 2). Distributions show an isolated pattern without overlapping, and the terminations are in step and snap. In addition to this, a poor development of micro-scarring was observed, presenting a similar pattern in macro-scars, only appearing alongside other traces, mainly, polishes (Fig. S3A). Microscopic use-wear analysis (Table 3) revealed the development of polish in patches (Fig. S3B and S3C) with a rough to smooth surface texture. The rough polish corresponds to the lower areas of the microtopography with a bright reflection, while the smooth polish is clearly developed on the uppermost areas of the microtopography with a very bright reflection (Fig. S3C and S3D). The development of lineal components, striations, and 


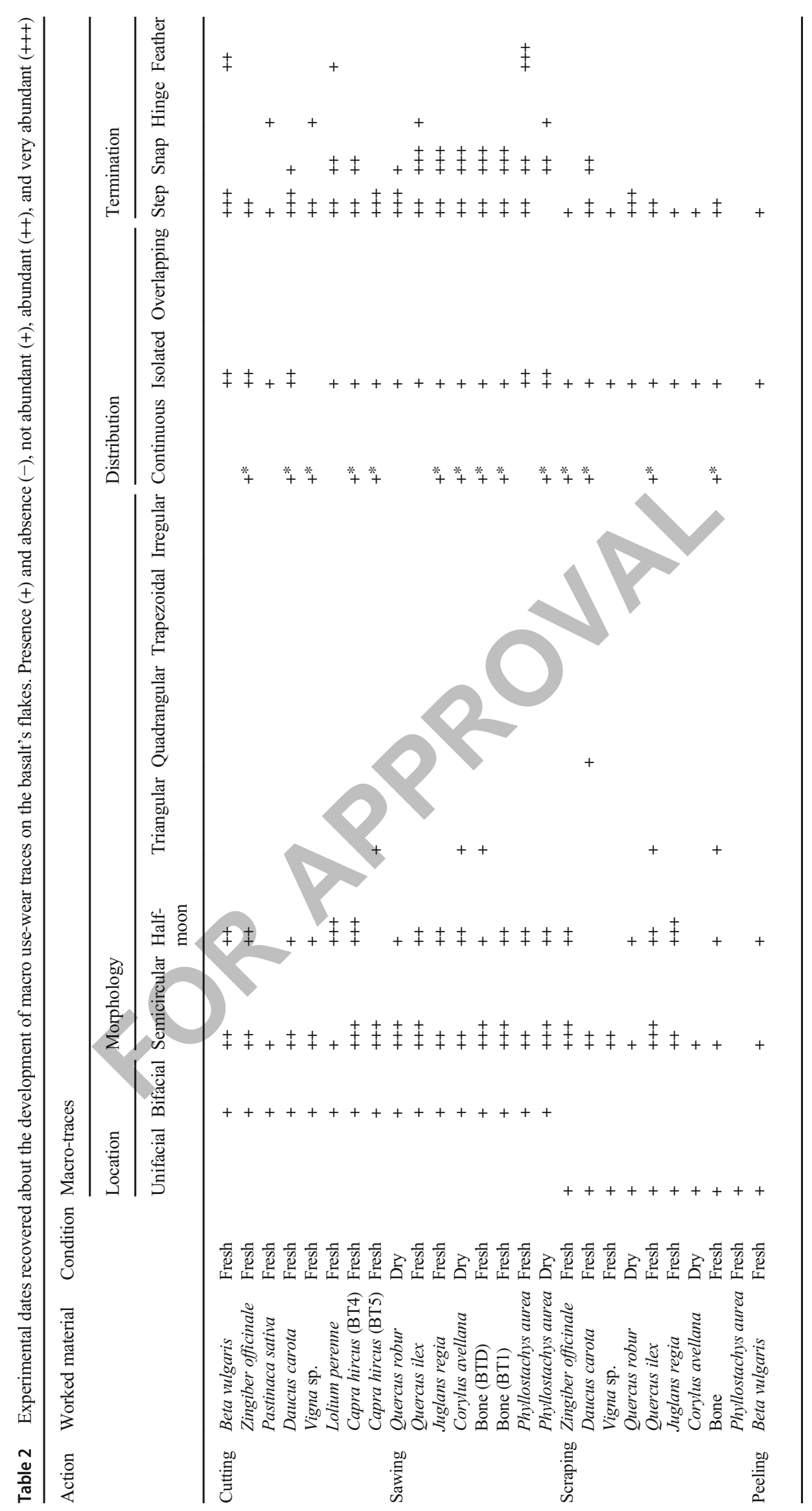


Table 3 Micro use-wear trace s dates recovered on experimental basalt flakes. Presence $(+)$ and absence ( () , not abundant (+), abundant (++), and very abundant (+++)

\begin{tabular}{|c|c|c|c|c|c|c|c|c|c|c|}
\hline \multirow[t]{3}{*}{ Action } & \multirow[t]{3}{*}{ Worked material } & \multirow[t]{3}{*}{ Condition } & \multicolumn{8}{|c|}{ Micro-traces } \\
\hline & & & \multirow[t]{2}{*}{ Striations } & \multirow[t]{2}{*}{ Lineal components } & \multirow[t]{2}{*}{ Pits } & \multirow{2}{*}{$\begin{array}{l}\text { Micro- } \\
\text { scarring }\end{array}$} & \multirow[t]{2}{*}{ Rounding } & \multicolumn{3}{|l|}{ Polish } \\
\hline & & & & & & & & Undulating & Smooth & Rough \\
\hline \multirow[t]{8}{*}{ Cutting } & Beta vulgaris & Fresh & + & + & & + & + & + & & ++ \\
\hline & Zingiber officinale & Fresh & + & + & & + & + & ++ & & ++ \\
\hline & Pastinaca sativa & Fresh & & & & + & + & + & & ++ \\
\hline & Daucus carota & Fresh & + & ++ & & + & + & ++ & ++ & \\
\hline & Vigna sp. & Fresh & + & ++ & & + & ++ & & +++ & \\
\hline & Lolium perenne & Fresh & + & & & & + & & + & \\
\hline & Capra hircus (BT4) & Fresh & & ++ & & + & + & ++ & + & +++ \\
\hline & Capra hircus (BT5) & Fresh & & & & & & & & \\
\hline \multirow[t]{8}{*}{ Sawing } & Quercus robur & Dry & + & + & & + & + & ++ & & +++ \\
\hline & Quercus ilex & Fresh & + & & & ++ & ++ & + & & ++ \\
\hline & Juglans regia & Fresh & & +++ & & ++ & + & & ++ & +++ \\
\hline & Corylus avellana & Dry & & + & & ++ & & & & ++ \\
\hline & Bone (BTD) & Fresh & + & ++ & & ++ & ++ & ++ & & +++ \\
\hline & Bone (BT1) & Fresh & + & ++ & & ++ & 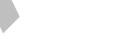 & & & ++ \\
\hline & Phyllostachys aurea & Fresh & ++ & + & & + & ++ & & ++ & +++ \\
\hline & Phyllostachys aurea & Dry & + & & & ++ & + & & + & ++ \\
\hline \multirow[t]{9}{*}{ Scraping } & Zingiber officinale & Fresh & + & + & & + & + & ++ & & + \\
\hline & Daucus carota & Fresh & & + & & + & + & +++ & + & ++ \\
\hline & Vigna sp. & Fresh & & & & + & & & & + \\
\hline & Quercus robur & Dry & & +++ & & + & + & ++ & & +++ \\
\hline & Quercus ilex & Fresh & & & & + & & & & ++ \\
\hline & Juglans regia & Fresh & & & & + & & & & ++ \\
\hline & Corylus avellana & Dry & & & & + & & & & ++ \\
\hline & Bone & Fresh & + & & & ++ & + & & + & +++ \\
\hline & Phyllostachys aurea & Fresh & & 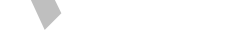 & & + & + & & + & ++ \\
\hline Peeling & Beta vulgaris & Fresh & & + & & + & + & +++ & & + \\
\hline
\end{tabular}

pits has not been observed on the used edges. Only a few were located with small and poorly developed patches of edge rounding in association with polished areas (Fig. S3A).

Sawing fresh cane (Phyllostachys aurea): this activity was carried out with two flakes for a time period of 22 and $30 \mathrm{~min}$, respectively (EXP110/BT1 and EXP128/BT1). Scar formation for these pieces is bifacial with half-moon and semicircular morphology (Table 2). Their distribution is isolated, without overlapping, with feather, step, and, less abundant, snap terminations. Considering the micro-scar formation, these appear isolated and not overlapped yet are in association with polished areas along the used edge. Micro-traces (Table 3) are well developed in some areas (Fig. 4a). The surface texture of these polishes presents a transition from rough to smooth polish. Rough polish is in the lower areas of the microtopography, while the smooth polish is formed in the upper areas (Fig. 4b). Furthermore, the polish is presented as bright (Fig. $4 \mathrm{~b}$ and c) to very bright (Fig. 4a), depending on the degree development (Fig. 4a). In association with the polished areas, some crystals were observed with few parallel striations that indicate the movement of this activity (Fig. 4 a and c). Additionally, there are rounded areas linked with these polishes, yet when observed are normally restricted to the very edge of the piece (Fig. 4b).

Sawing dry cane (Phyllostachys aurea): this activity was carried out using two flakes for time periods of 2 and $60 \mathrm{~min}$ (EXP171/BT1 and EXP108/BTD). Data obtained was through experiments made with BT1, considering the limited amount of information produced with BTD flakes. Development of scars appear bifacial with a predominance of semicircular and, to a smaller degree (Table 2), half-moon morphologies (Fig. S4A and S4B). These scars appear isolated yet some areas present clustered scars without overlapping. 


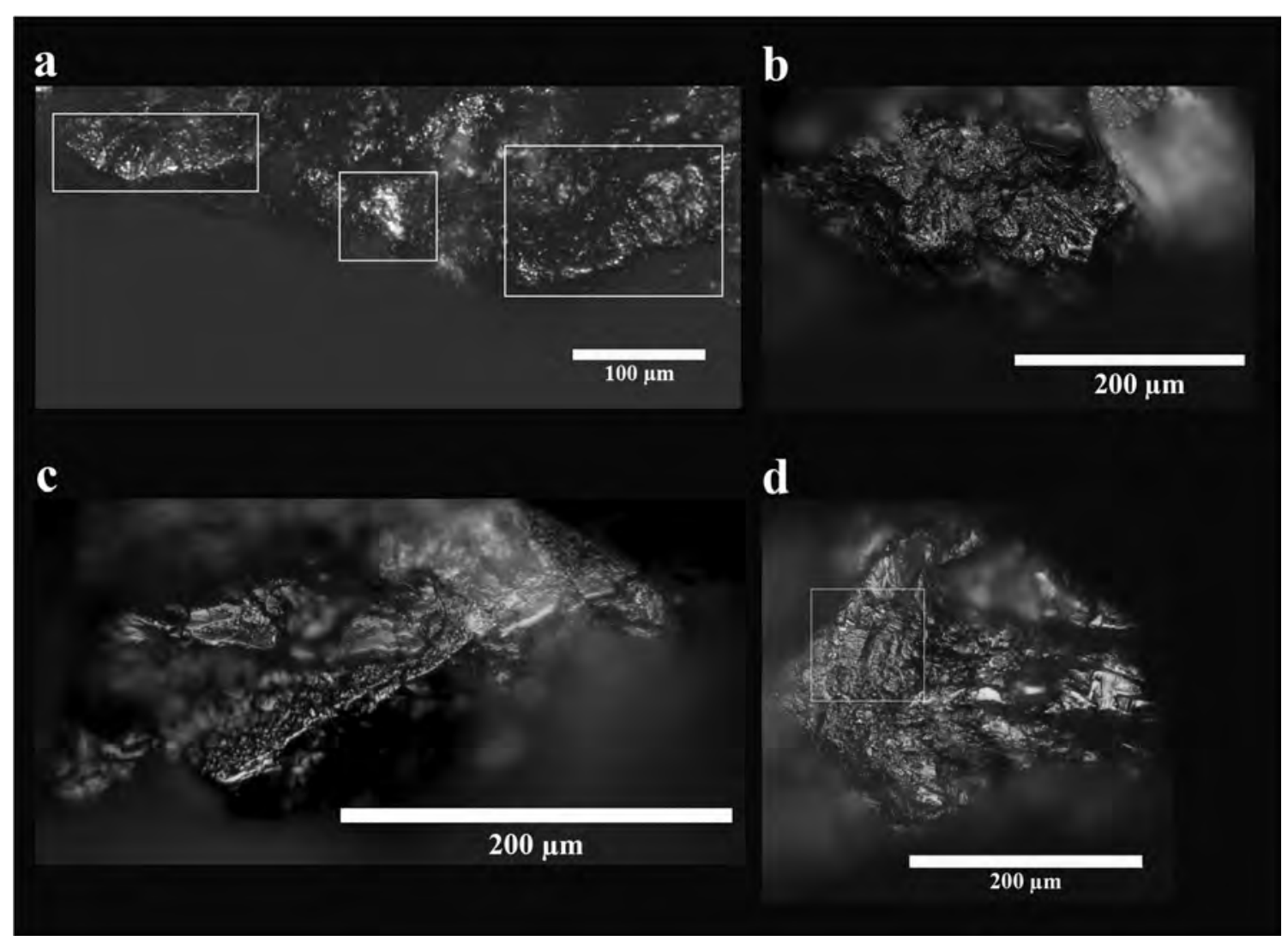

Fig. 3 Traces after cutting Lolium perenne for 30 min with BT1: a patches of polish along the used edge; $\mathbf{b}$ undulating to smooth polish; $\mathbf{c}$ undulating polish with formation of few and short lineal components; $\mathbf{d}$ smooth polish forming a poor rounded area on the most exposed points

Scars present a certain dominance of hinge and snap terminations. Unlike the case of other activities developed in this experiment, sawing dry cane produced a larger quantity and size of scars, usually appearing oriented. At a microscopic scale, micro-scars appear isolated and without overlapping yet are not strictly related to other micro-traces.
Fig. 4 Traces after sawing fresh Phyllostachys aurea for $30 \mathrm{~min}$ with BT1: a very bright smooth polish in association with a few parallel striations; $\mathbf{b}$ patch of smooth and bright polish that created rounded points; $\mathbf{c}$ bright undulating polish with the

formation of lineal components and a few striations

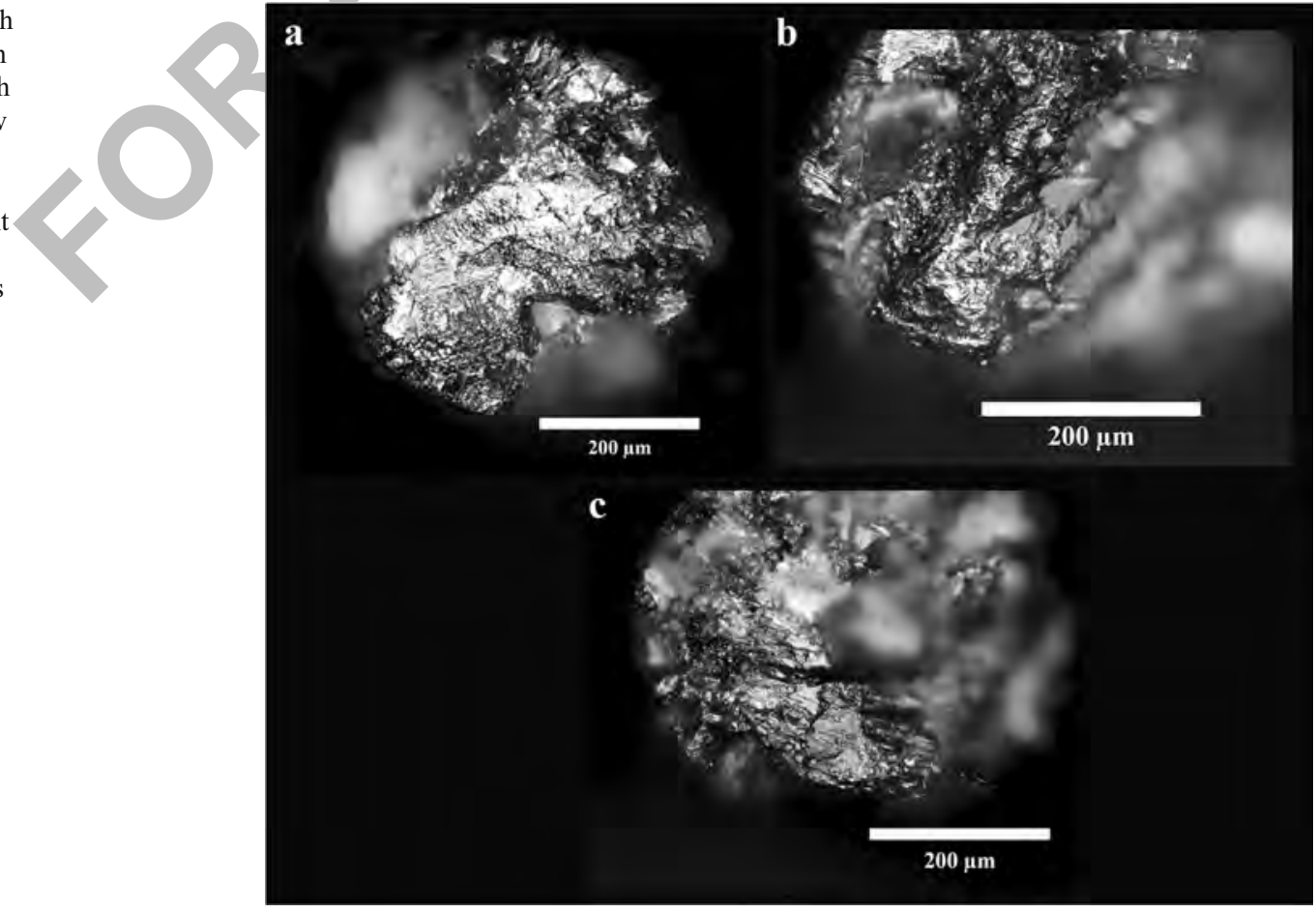


According to results obtained during micro-analysis (Table 3), a clear formation of rather invasive polished areas along the edge was observed (Fig. S4C, S4D, and S4E). Polish is smooth and very bright (Fig. S4C, S4D, S4E, and S4F) with some patches of mate or bright rough polish (Fig. S4D and S4G). Some striations appear in association with these polishes oriented obliquely to the edge (Fig. S4C, $\mathrm{S} 4 \mathrm{D}$, and $\mathrm{S} 4 \mathrm{G}$ ). Finally, some edge rounding is also associated with this polish.

\section{USOs}

Cutting USOs (Beta vulgaris, Zingiber officinale, Pastinaca sativa, Daucus carota, and Vigna sp.): the activities for cutting (bidirectional) tubers were made with six flakes from 8 to 60 min (EXP105/BTD; EXP115/BT1; EXP126/BT1; EXP127/BT1; EXP145b/BT1; EXP147/BT1; EXP148/BT1; EXP168/BT1, and EXP178/BT1). Once again, the description is made with the results obtained with BT1, considering the limited amount of information produced with BTD flakes. Similarities are observed when comparing with the overall results from other activities (Table 2). The location of the scars is bifacial in all flakes. Their morphology presents an abundant development of semicircular scars and more occasionally half-moon scars (Fig. 5a and 5b). The differences in macrotrace formation are related with the resistance of each type of tuber (Table 2). For example, Pastinaca sativa is a very soft tuber; therefore, scar formations are scarce. In the case of halfmoon scars, they are more developed for pieces used for cutting the hardest and most fibrous tubers, such as Zingiber officinale and Beta vulgaris (Fig. 6a; Fig. S5A and S5B). Additionally, these scars usually appear in isolation, with some examples clustered and no overlapping of scars. Terminations are usually in step (Fig. 7Aa). Concerning the formation of micro-scarring, data shows the same formation patterns for macro-scarring.

At high magnification, an important development of micro use-wear traces was generally observed (Table 3). Polishes are well developed on all flakes, with some case appearing more invasive along the used edge (Figs. 5Ac-f, $5 \mathrm{Bg}-\mathrm{j}$ and $5 \mathrm{Ck}-\mathrm{n}$ ). Areas with rough (Fig. 5Ck; Fig. S5C, S5E, and S6A), undulating (Fig. S5F and S6B), and smooth polish (Figs. 5Ad-e, 5Cl-n, 7Ae, 7Bf, and 7Bg) were frequently observed, with some cases presenting polishes that indicate the orientation of the piece during the activity (Fig. $5 \mathrm{Cl}$ ). These variations could be related to the different nature of the tubers (water content, hardness) and with the intensity of the activity being performed. Processing Zingiber officinale (Fig. 6 b, c, and d), Beta vulgaris (Fig. S5D and $\mathrm{S} 5 \mathrm{~F}$ ) and Pastinaca sativa (Fig. S6A) develops a bright polish, while Vigna sp. and Daucus carota develops a very bright polish (Figs. 5Ad, $5 \mathrm{Ae}$ and $7 \mathrm{Ab}, 7 \mathrm{Ae}$ ). Except for the softer USO (Pastinaca sativa), pieces used for processing the rest of tubers present lineal components, especially in activities on the more abrasive tubers (Figs. 5Bh, 5Cl; 6b, d and 7Ae; Fig. $\mathrm{S} 5 \mathrm{E})$. The same can be said in the case of striations (Figs. 5Bi, 5Cl and 7Ad, 7Bg, 7Bh; Fig. S5D), which appear in low numbers, usually appearing short and oblique. The frequency of these striations is low and has a shorter length. The orientation of all traces is oblique. Edge rounding was identified for the processing of Vigna sp. and Zingiber officinale (Figs. 6c and 7Ae and 7Bf-h).

Peeling Beta vulgaris: one flake was used for peeling with a low cutting angle Beta vulgaris for 15 min (EXP106/BTD). Scars developed unifacially, isolated, without overlapping, and with half-moon morphology and step terminations (Table 2). In general terms, the formation of scars is very low, yet this can be related with a short use time, even though in the time taken to perform the activity 5 big Beta vulgaris were peeled. Likewise, the development of micro-scarring is also low, presenting the same patterns as macro-scarring. Microscopic observations show a well-developed undulating polish formed along the edge (Fig. 8a) in association with patches of rough, dull polish (Fig. 8b; Table 3). In combination with the polish, the formation of few transverse lineal components was noted (Fig. 8a). Finally, some edge rounding along the edges were observed (Table 3).

Scraping tubers (Zingiber officinale, Daucus carota, and Vigna sp.): five flakes were used for scraping tubers and the removal of the peel, for time periods of $38,40,44,50$, and 60 min (Table 2) (EXP132/BT1; EXP170/BT1; EXP175/ BT5; EXP176/BT1, and EXP177/BT2). The location of scars are unifacial on the three types of basalts used (BT1, BT2, and BT5). Morphology presents abundance of semicircular scars (Fig. S7A, S8A, and S9A). Their distribution is characterized by an isolated pattern (Fig. S7A) with few patches of continuous scars (Fig. S8A and S9A). The common termination is step for both basalt types (Fig. S7A, S8A, and S9A).

Micro-analysis reveals similar trace development patterns, yet some differences have been observed that depend on the basalt type (Table 3). In the case of BT2 and BT5, a poor and isolated development of polish was observed (Fig. S7B, S8A, S8B, and S8C). Surfaces, regardless of the time of use, only present a rough polish with few patches of smooth polish on the uppermost microtopographic areas (Fig. S7B and S8B). The last characteristic identified for this basalt type is the reflection, which is always bright.

In the case of flakes made on BT1, a different micro-wear formation was observed (Table 3). The polish is better developed along the used edge, presenting rough (Fig. 9a), undulating, and very brightly polished areas (Fig. 9a-c; Fig. S9B). In association with polished areas, abundant lineal components with oblique orientations were also observed (Fig. 9b; Fig. S9B). Although the formation of pits and striations was absent, in each case, areas with edge rounding were located. 


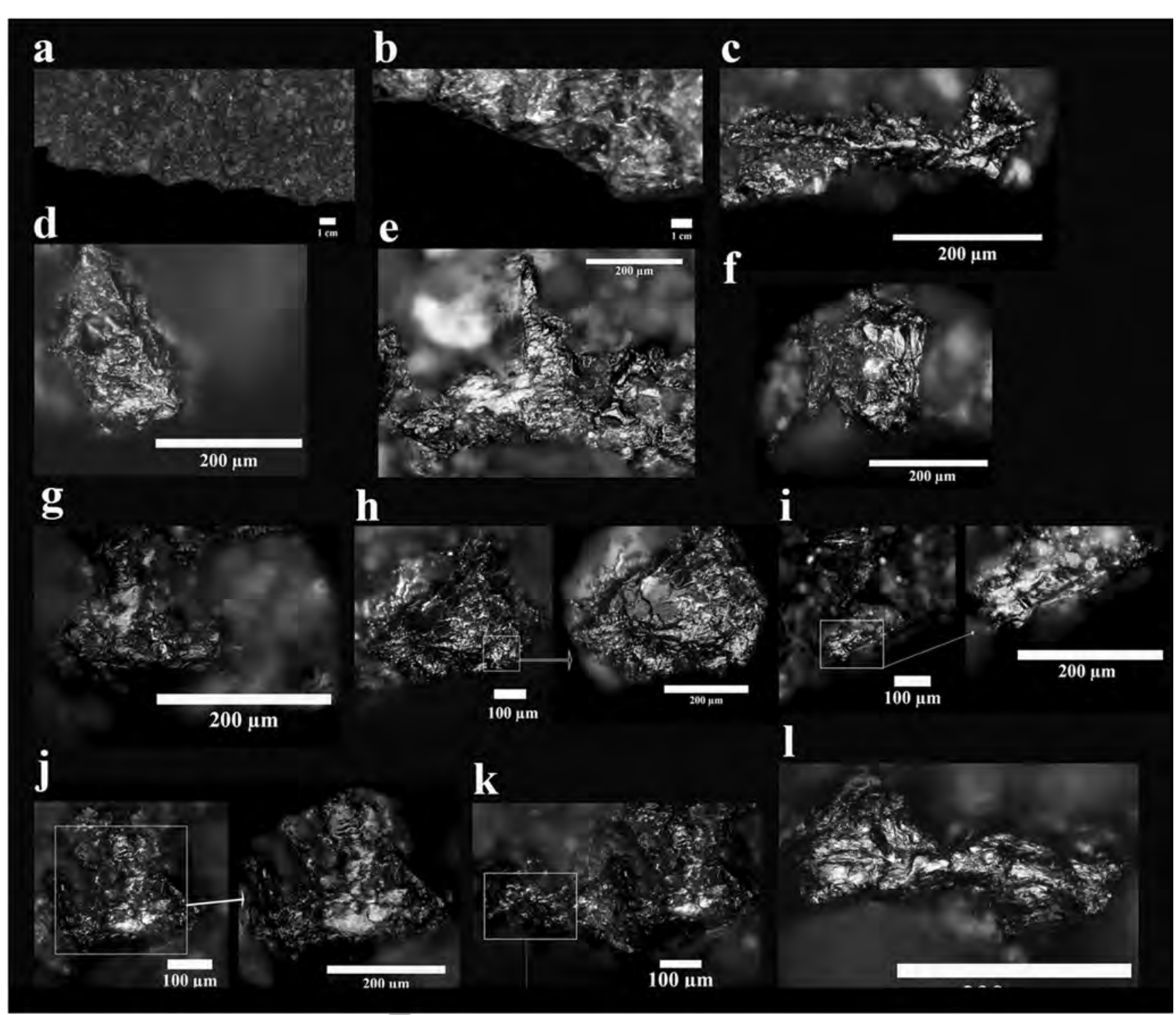

Fig. 5 Fig. 5A Traces after cutting Vigna sp. for 50 minutes with BT1: a isolated and no overlap macro scars with semicircular and half-moon morphologies; $\mathbf{b}$ half-moon and semicircular macro scars with step and snap terminations; $\mathbf{c}$ polish development on the top points of the surface; d rough to smooth polish; e very bright rough to smooth polish; f small patch with smooth polish development; Fig. 5B Traces after cutting

\section{Wood}

Sawing dry hard wood (Quercus robur with bark): for this activity, two flakes were used for time periods of 30 and 60 min (Table 2) (EXP0072/BTD and EXP0089/BTD). The location of scars is bifacial, and the most abundant morphology is semicircular. Half-moon types are present yet to a lesser degree (Fig. 10a). The scars appear isolated and without overlapping. The terminations are in step (Fig. 10b). Microscarring is not abundant and follows the same pattern as macro-scarring.

The formation of micro use-wear traces is clear along the used edges (Table 3). The most developed trace is the
Vigna sp. for 50 min with BT1: g small patch with rough to smooth polish; Fig. 5C Traces after cutting Vigna sp. for 50 minutes with BT1: $\mathbf{k}$ disperse areas with mate rough to very bright smooth polishes; $\mathbf{I}$ well development of very bright smooth polish with certain orientation; m very bright oriented smooth polish; $\mathbf{n}$ rough to smooth very bright polish

formation of rather invasive polished surfaces, with a combination of rough, undulating, and smooth polishes (Fig. $10 \mathrm{c}, \mathrm{d}$, $\mathrm{e}$, and $\mathrm{f}$ ). Rough polish forms in the lower areas of the microtopography, while smooth and undulating patterns appear in the uppermost areas, being the undulating polish the best developed one. The development of these polished areas also produces some rounding of edges (Fig. 10c). Polished areas are moderately bright (Fig. 10d) and develop lineal components parallel to the used edge (Fig. 10e). A few striations also appear in association with the polish, parallel to the edges (Fig. 10f).

Scraping dry hard wood (Quercus robur with bark): dry Quercus robur was scraped using two flakes during 30- and 


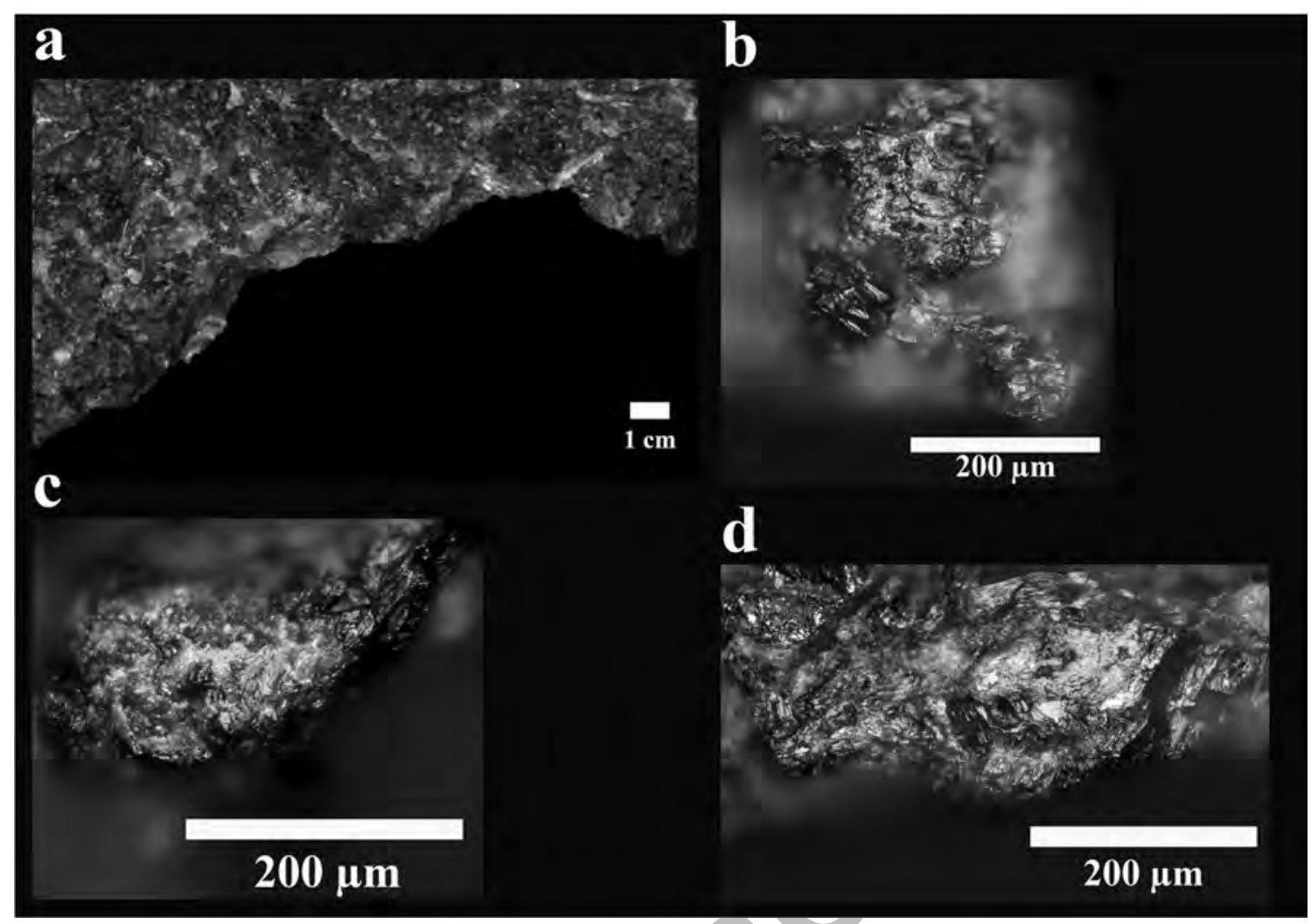

Fig. 6 Traces after cutting Zingiber officinale for 60 min with BT1: a isolated macro-scars with half-moon and triangular morphologies; b oriented rough to smooth polish; c very bright rough to smooth polish with

60-min intervals (Table 2) (EXP0091/BTD and EXP0093/ BTD). Distribution of scars are unifacial, with an abundance of semicircular and half-moon morphologies with a few triangular scars (Fig. $11 \mathrm{a}$ and b). Scar distributions tend to be isolated with some patches of continuous scars ( 2 or 3 scars) without overlapping. Scar terminations in step and hinge are very common. Micro-scarring analysis show some patches with a tendency to be isolated, while few presented continuous patterns ( 2 or 3 scars) and without overlapping. Development of micro use-wear traces present a clear trend from rough to smooth (Fig. 11c) and undulating polishes (Fig. 11d) (Table 3). In accordance with these results, brightness is also varied with mixtures of bright (Fig. 11e) and matt areas (Fig. 11f). Oblique lineal components (Fig. $11 \mathrm{~d}$ and e) and scattered edge rounding are notably observed in association with polish.

Sawing fresh hard wood (Quercus ilex with bark): the formation of scars on one flake (BT1) that was used for $25 \mathrm{~min}$ (Fig. 12A1) (EXP0188/BT1) presented bifacial and abundant semicircular and half-moon scar morphologies (Fig. 12A2) (Table 2). The distribution is isolated with no overlapping patterns during the first $5 \mathrm{~min}$ of use, but for 15 and $25 \mathrm{~min}$ of use, the formation of a few continuous scars was noted ( 2 or 3) without overlapping (Fig. 12A2 and A3). These scars show a high number of snap and step terminations, with few hinges the formation of edge rounding; $\mathbf{d}$ very bright rough to smooth oriented polish in association with lineal components

(Fig. 12A4). The analysis of micro-scarring presents a similar pattern to macro-scars, yet at no point were continuous scars observed along the used edges.

At a microscopic scale, a poor development of polish was observed with a combination of rough and undulating surface textures (Fig. $12 \mathrm{~B}$ and C) (Table 3). Additionally, polish presents a tendency to develop a mate reflection. In association with the formation of rough polish, scattered areas of edge rounding were also observed (Fig. 12C).

Scraping fresh hard wood (Quercus ilex with bark): macrotraces observed on one flake used for the scraping fresh Quercus ilex for 32 min (Fig. S10A1) (EXP0112/BT1) present unifacial trace patterns (Table 2 ) frequently observed with halfmoon and an abundance of semicircular morphologies (Fig. $\mathrm{S} 10 \mathrm{~A} 2)$. Distributions are isolated in combination with few patches of continuous scars ( 2 or 3 scars) and no overlapping. These scars frequently present step and snap terminations (Fig. S10A3). Micro-scarring patterns present an isolated distribution with some patches of continuous scars without overlapping.

The development of micro use-wear traces is poor with scarce formation of polishes on the lowermost areas of the microtopography (Fig. S10B) (Table 3). The surface texture is rough with a bright reflection. In association with the polish, we observe the formation of a few oblique lineal components (Fig. S10C). 


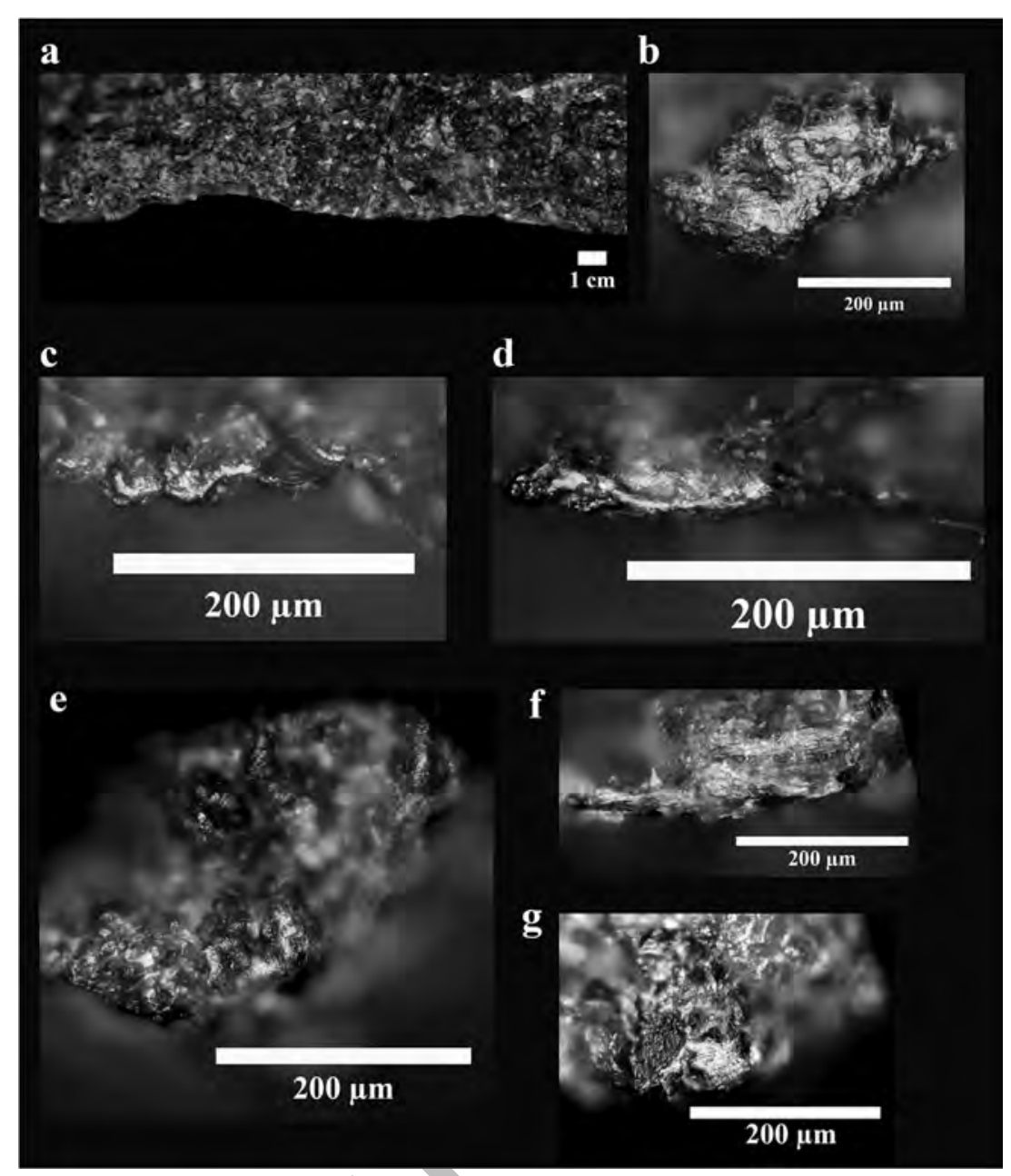

Fig. 7 Fig. 7A Traces after cutting Daucus carota for 60 min with BT1:a isolated macro-scars with step terminations; $\mathbf{b}$ bright smooth polish; $\mathbf{c}$ and d small bright patch of smooth polish with edge rounding; $\mathbf{e}$ formation of bright rough areas on the uppermost points of the surface microtopography;

Sawing fresh soft wood (Juglans regia with bark): this activity was carried out with one flake (EXP0189/BT5) for a

Fig. 7B Traces after cutting Daucus carota for 60 minutes with BT1: f bright smooth polish formation in association with few striations; $\mathbf{g}$ bright rough polish to smooth polish in association with few and short striations; $\mathbf{h}$ bright smooth polish in association with few striations

duration of 31 min (Fig. 13A1) (Table 2). Results show a bifacial distribution of scars. The most common morphology

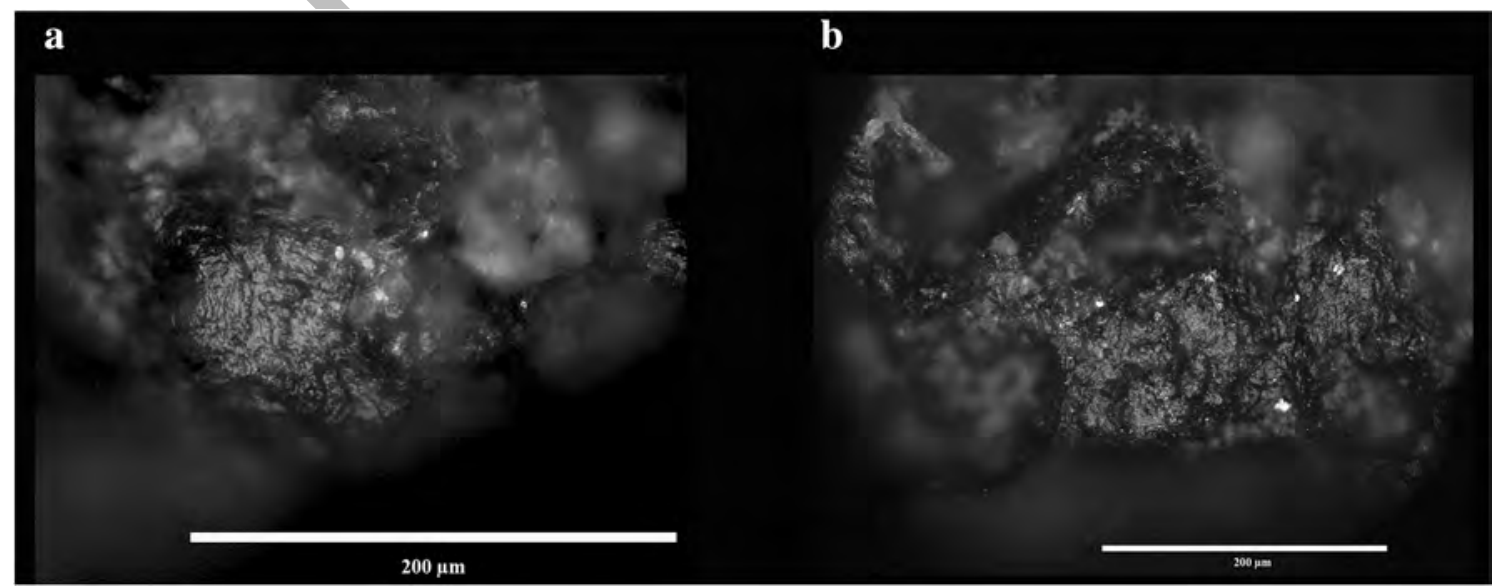

Fig. 8 Traces after peeling Beta vulgaris for $15 \mathrm{~min}$ with BTD: a mate undulating polish in association with lineal components; b patches of mate rough polish 
Fig. 9 Traces after scraping Daucus carota for 38 min with BT1: b bright undulating to smooth polished area; $\mathbf{b}$ oriented very bright rough to smooth polish; and $\mathbf{c}$ very bright undulating to smooth polish

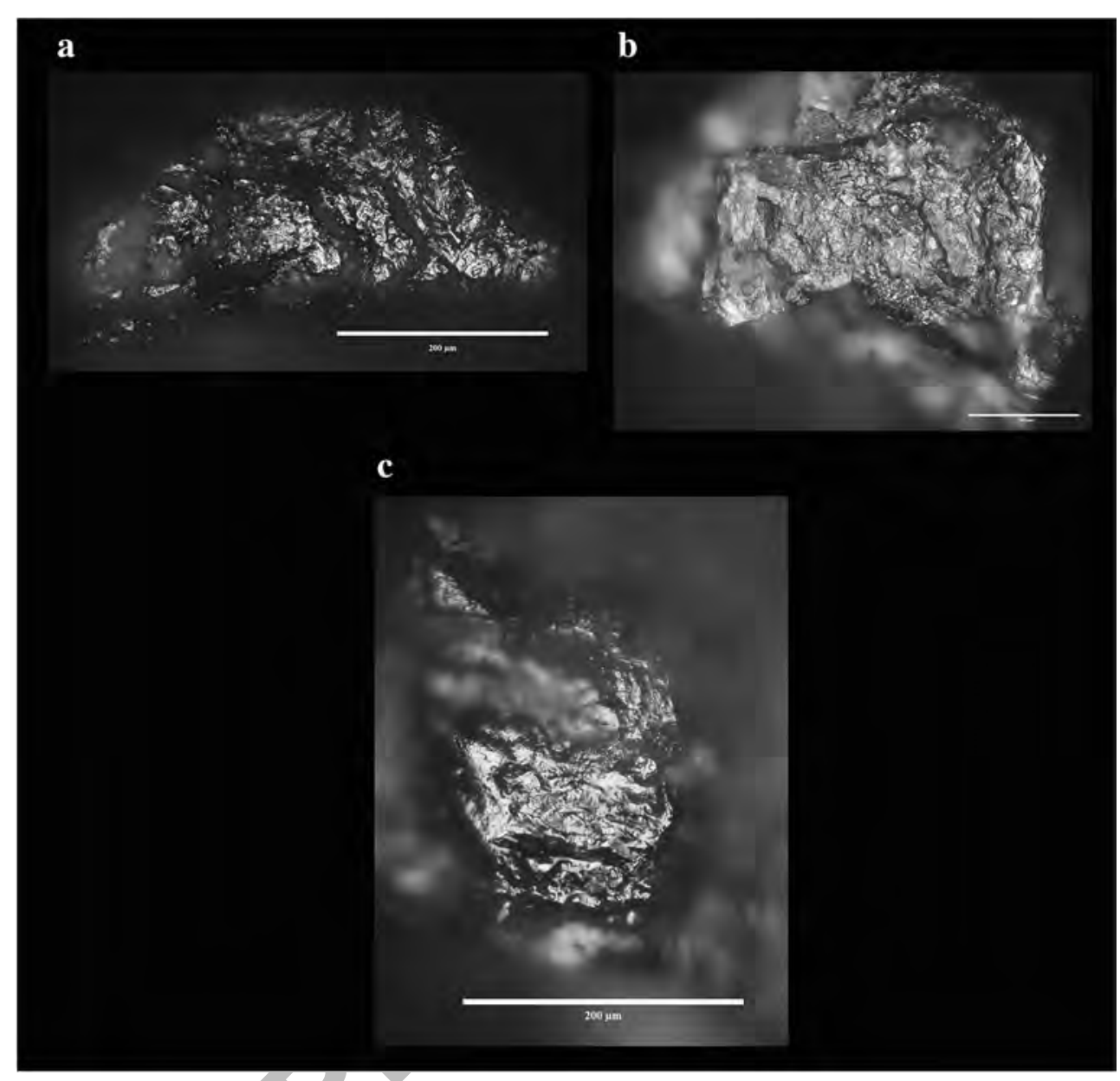

of these scars is semicircular and half-moon (Fig. 13A2). In terms of distribution, we observe an abundant presence of isolated scars and a few continuous patches with 2 or 3 scars and no overlapping patterns. Terminations are mostly snap and step (Fig. 13A3). Micro-scarring is present along the used edge with an abundance of isolated scars and a few continuous patches without overlapping.

According to the micro-results obtained, we observed an abundance of points with bright rough and smooth polishes (Fig. 13 B and C) (Table 3). Lineal components are scarce, but parallel developments are observed in relation with smooth polish (Fig. $13 \mathrm{C}$ and D). Finally, in association with polished areas, the formation of scattered edge rounding was observed, especially in the case of smooth polish.

Scraping fresh soft wood (Juglans regia with bark): scar development on one flake (EXP0190/BT5) used for $31 \mathrm{~min}$ (Fig. S11A1) is unifacial in nature (Table 2). Common scar morphologies include semicircular with an isolated and no overlapping distribution (Fig. S11A2). Moreover, terminations are mostly snap (Fig. S11A3). In addition to this, the formation of isolated and no overlapping micro-scarring patterns was noted.
In the case of micro-analysis, observations revealed a scattered rough polish formation with a bright surface (Fig. S11B) (Table 3).

Sawing dry soft wood (Corylus avellana with bark): in this activity, one flake (EXP091/BT5) was used for 9 min (Fig. S12A1). In this case, the time of use was short due to fracturing of the edge during sawing. The edge damage presents bifacial scar formation with an abundance of semicircular and half-moon morphologies in combination with some triangular (Table 2). Their distribution is mostly isolated with no overlapping, but in some points of the used edge, continuous patches of scars were noted (2/3 scars) (Fig. S12A2). Terminations include step and some snap. Micro-scarring appears with an isolated distribution and no overlapping pattern in combination with a few patches of continuous scars ( 2 or 3 scars). Additionally, micro use-wear studies revealed a poor extension of the polish along the edge (Table 3). Furthermore, in association with the polish formation, some oblique lineal components were observed (Fig. S12B).

Scraping dry soft wood (Corylus avellana with bark): for scraping dry Corylus avellana, one flake (EXP0192/BT5) was restricted to $15 \mathrm{~min}$ of use due to edge rounding (Fig. S13A1). The edge presents a unifacial location of semicircular 
Fig. 10 Traces after sawing dry Quercus robur for $60 \mathrm{~min}$ with BTD: a semicircular and halfmoon macro-scar morphologies; b macro-scars with step terminations; $\mathbf{c}$ bright rough to smooth polish with edge rounding development; $\mathbf{d}$ mate rough polish to very bright smooth polish; $\mathbf{e}$ bright undulating polish to very bright smooth polish in association with scattered edge rounding and lineal components; $\mathbf{f}$ bright undulating polish to very bright smooth polish in association with few and short striations

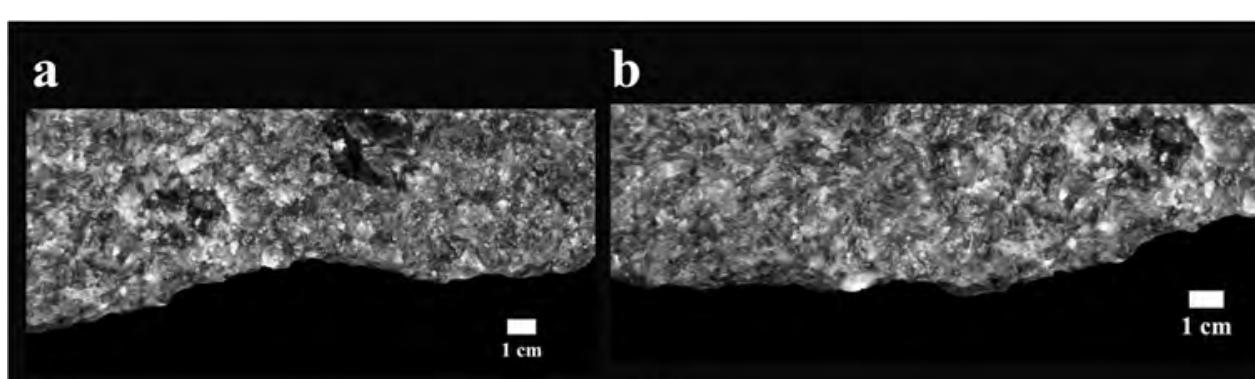

c

d

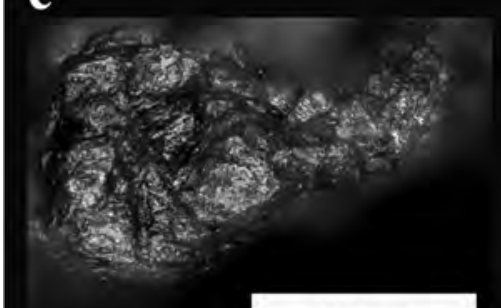

$200 \mu \mathrm{m}$

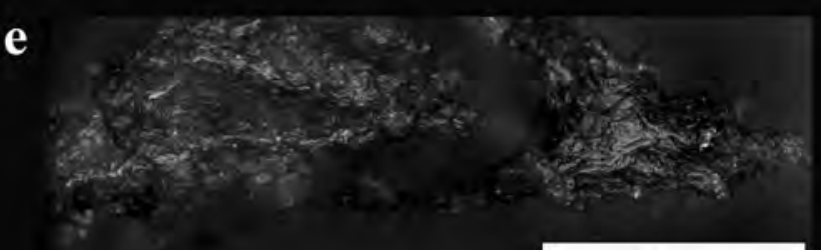

$200 \mu \mathrm{m}$

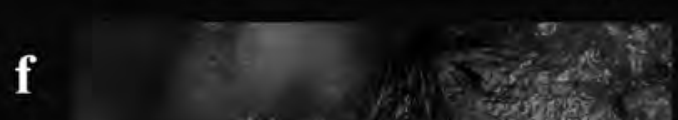

morphologies (Fig. S13A2) with isolated no overlapping distributions and step and snap terminations (Fig. S13A3) (Table 2). In addition to this, a low development of isolated and no overlapping micro-scarring was noted. Micro use-wear presents a poor extension of rough polish (Fig. S13B) with a bright surface yet without traces that indicate the working movement (Table 3).

\section{Butchering}

Activities were performed using eleven flakes during 16-, 23-, 33-, 50-, 57-, and 60-min intervals with different types of basalts (Table 2) (EXP169/BTD; EXP0174/BT4; EXP0179/ BT2; EXP0180/BT4; EXP0181/BT4; EXP0182/BT4; EXP0183/BT4; EXP0184/BT4; EXP0185/BT5; EXP0186/ BT5; EXP0187/BT2). For the basalt type 4, we observed the formation of bifacial scars with semicircular and, less common, half-moon morphologies (Fig. 14a; Fig. S14A). The distribution pattern is isolated with few patches of continuous scars (2 or 3 scars) and no overlapping. Data reveals few scars with snap yet an abundance of step terminations. In the case of the two pieces worked with BT5, a low development of macro-traces was noted. The few scars formed show a semicircular morphology with an isolated and no overlapping distribution pattern. The termination of these scars is in step. In addition, the formation of scattered micro-scarring with the same pattern as macro-scarring was observed (Fig. 14d).

Analysis of the micro use-wear traces formed on both basalt types show a marginal extension of rough and undulating polishes (Fig. 14b, c, and d; Fig. S14B) (Table 3) with very bright surfaces (Fig. 14b; Fig. S14B). In association with undulating and rough polish, the development of a few parallel 


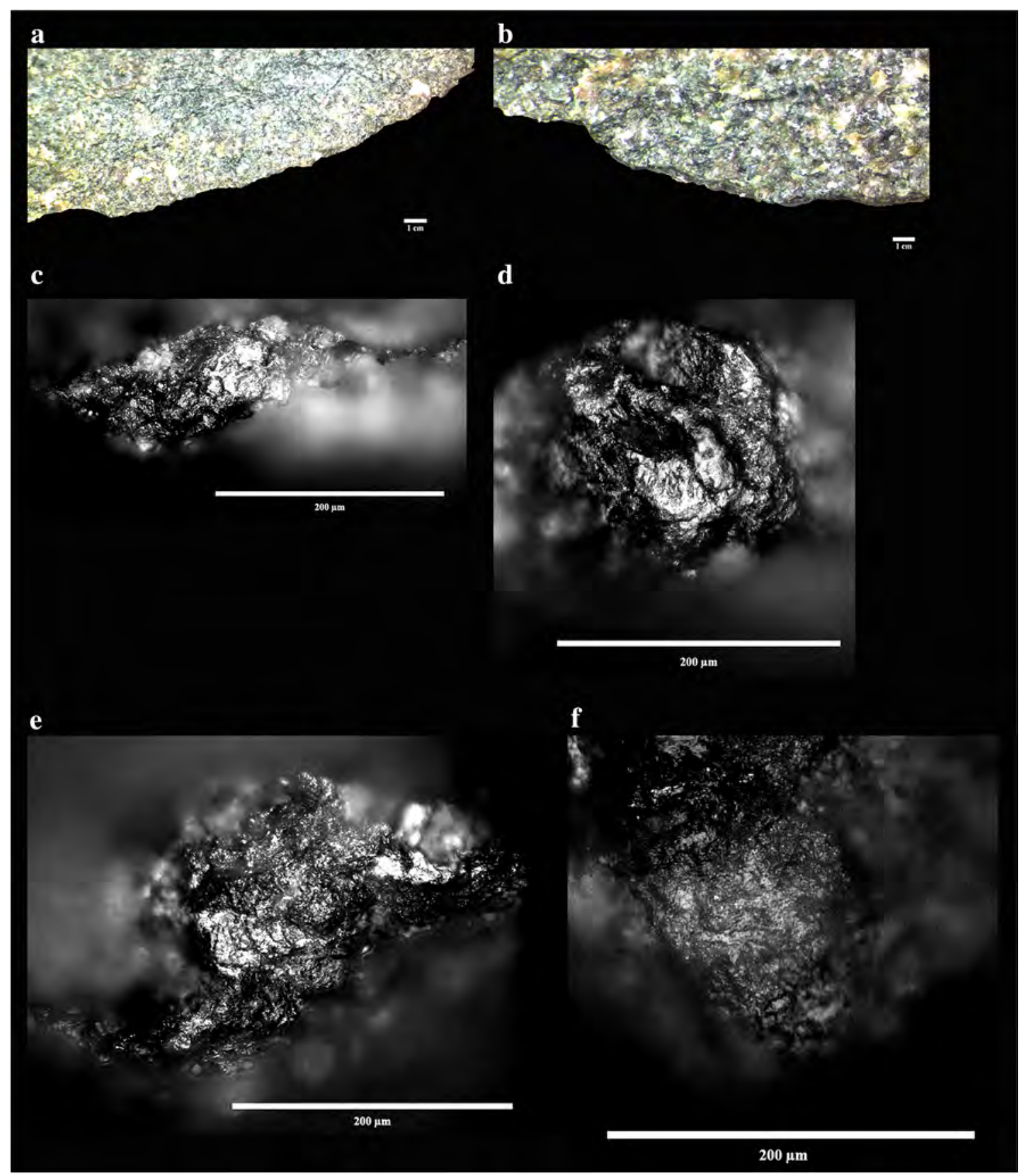

Fig. 11 Traces after scraping dry Quercus robur for 60 min with BTD: a isolated macro-scars with semicircular, half-moon, and triangular scars with snap and step terminations; b semicircular and half-moon scars with snap and step terminations; $\mathbf{c}$ and $\mathbf{d}$ bright rough polish to very bright

lineal components was detected (Fig. 14 b, c, and d). Moreover, in association with the polishes, the formation of points of scattered edge rounding was noted (Fig. S14B).

\section{Bone}

Sawing fresh bone: for this activity, three flakes were used for 30- and 60-min intervals with the Deba basalt type (EXP0096/ BTD and EXP0097/BTD) and 72 min with flakes made with smooth polish in association with oblique lineal components; e bright rough polish to very bright smooth polish; f mate rough polish to very bright smooth polish area with associated lineal components

basalt type 1 (EXP0114/BT1) (Table 2). The macro use-wear traces found on BTD are bifacial with mostly semicircular morphologies and some half-moon and triangular morphologies. Distribution patterns are mainly isolated with some patches of continuous scars (2 or 3 scars) and an abundance of snap and step terminations (Fig. 15a and S15A). Moreover, the formation of micro-scarring is present along the used edge with isolated and patches of continuous (3 or 4 scars) overlapping scars (Fig. S15B, S15C, S15D, and S15E). 


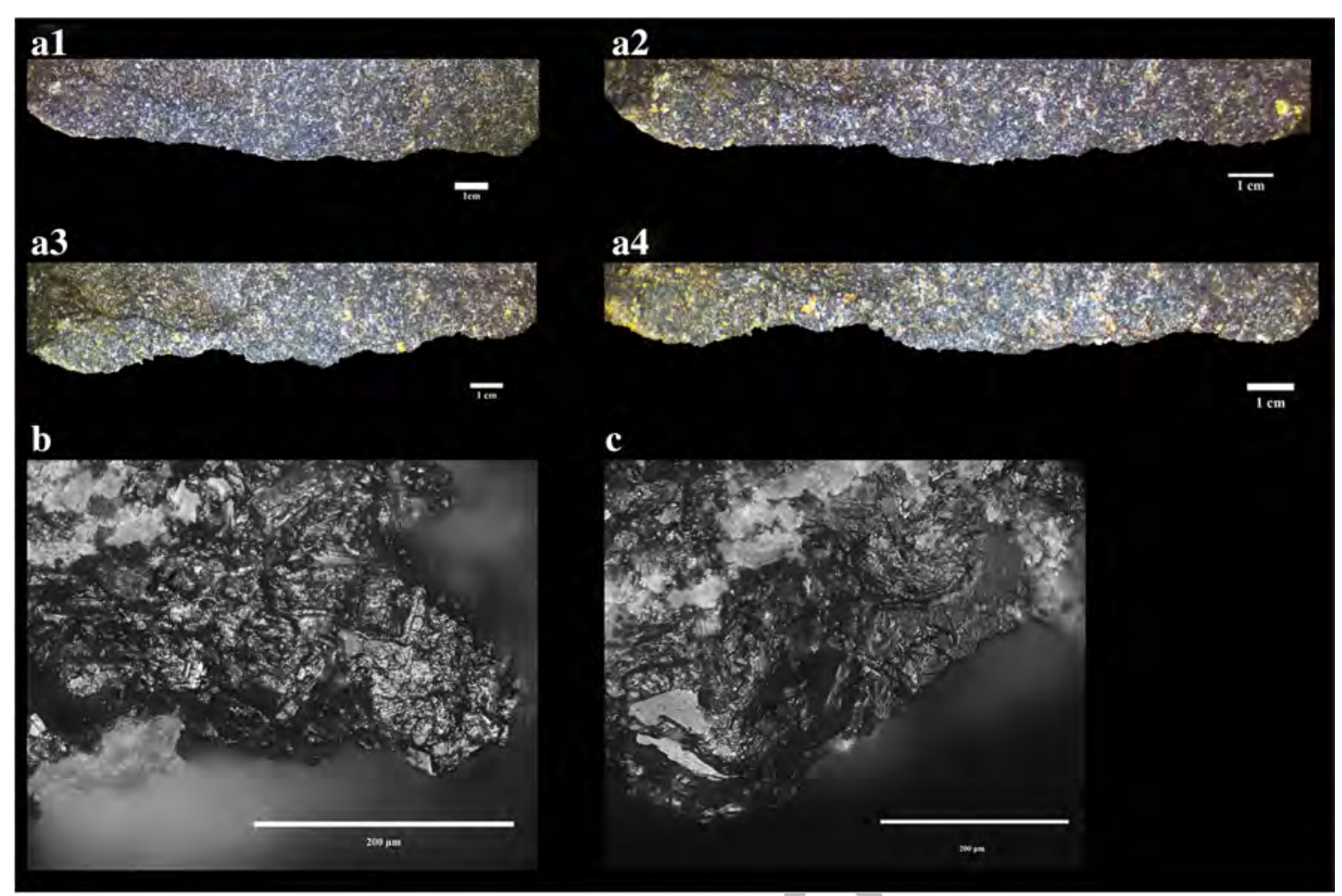

Fig. 12 Traces after sawing fresh Quercus ilex for 25 min with BT1: a1 isolated macro-scars; a2 semicircular and half-moon macro-scar morphologies; 33 isolated and overlap macro-scars; a4 combination of step, snap, and hinge macro-scars termination; b mate rough polish to bright undulating polish; $\mathbf{c}$ polish forming a rounded area
In terms of micro use-wear trace formation, the development of rough (Figs. 15Ac, 15Ad; Fig. S15B) and undulating polishes (Figs. 15Ab, 15Ae; Fig. S15D and S15E) (Figs. 15Ab, 15Ac, 15Ad, and 15Ae) (Table 3) were noted with a bright surface. In association with these polishes, the development of a few patches of parallel lineal components were also detected (Fig. 15Bf; Fig. S15E). In association with the polish, the formation of few and short striations with an oblique orientation were also documented (Fig. S15B) and the formation of pronounced rounded points (Fig. 15Bf-i; Fig. S15C and S15E).

The results obtained during the analysis of the pieces worked with BT1 reveal a bifacial distribution of macro-scars with an abundance of semicircular and half-moon morphologies (Fig. 16a) (Table 2). Their distribution is isolated with a few continuous patches ( 2 or 3 scars) and no overlapping. Furthermore, their termination is mainly in snap and step. A few areas of microscarring characterized by isolated pattern and a few patches with overlapping was also documented.

The results obtained during micro-analysis reveal a rough polish (Fig. $16 \mathrm{~b}$ and c) with a mate reflection. In association with these areas of polish, a few areas with parallel lineal components were noted (Fig. 16c). The formation of a few small parallel striations that correspond to the working movement (Fig. 16b) and moderate edge rounding (Table 3) was also noted.

Scraping fresh bone: the development of scars on two flakes used for $30 \mathrm{~min}$ (Table 2) (EXP0090/BTD and EXP0094/BTD) were seen to present a unifacial distribution along the used edge. Many semicircular morphologies were observed with a scarce presence of halfmoon and few triangular morphologies (Fig. 17a). Scar distribution patterns are isolated, but with some continuous patches $(2 / 3$ scars $)$ and no overlapping. Terminations are mainly of type snap and step (Fig. 17b). Moreover, micro-scarring present similar patterns to those observed in macro-scarring; characterized by isolated patterns with some continuous patches without overlapping.

The micro use-wear results show an abundance of patches of rough polish (Fig. $17 \mathrm{c}$ and $\mathrm{f}$ ) and a few zones with smooth polish (Fig. 17 e and f) (Table 3) with mate to bright surfaces. In relation to the formation of smooth polishes, short and a few oblique striations were observed (Fig. 17f). At the same time, the smooth polish observed was mostly in the form of scattered edge rounding (Fig. 17f). 


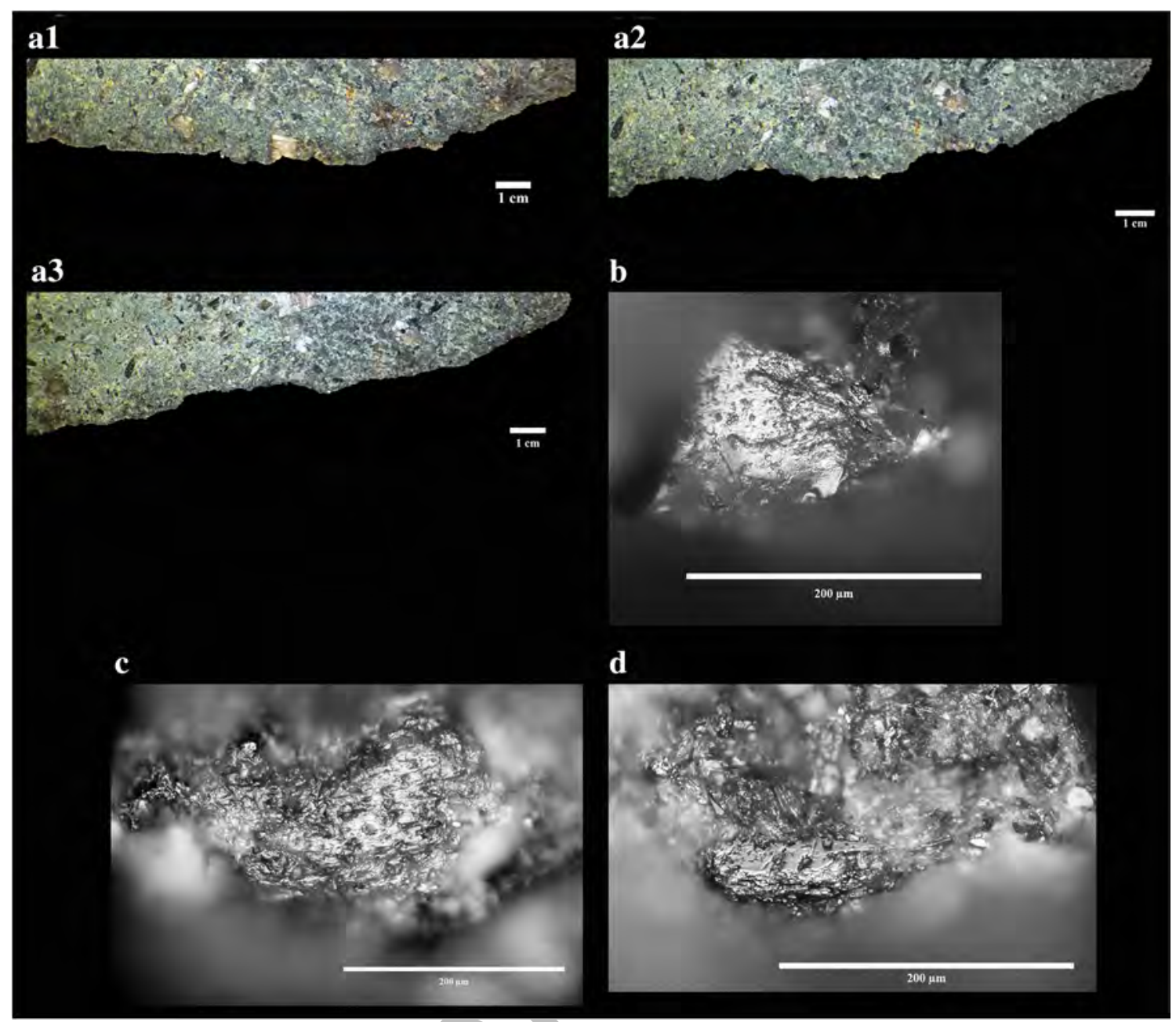

Fig. 13 Traces after sawing fresh Juglans regia for 31 min with BT5: $\mathbf{a} 1$ and a2 semicircular and half-moon macro-scar morphologies; $\mathbf{a} 3$ snap and step macro-scar terminations; b oriented rough to smooth polish; $\mathbf{c}$

\section{Discussion}

Regarding the petrological results, basalt mineralogy and internal structure could be directly affecting the development of use-wear traces. Data shows that basalts dominated by homogeneous, elongated crystals with scarce fine-grained groundmass, such as BT1 (Fig. 2a), develop better micro use-wear traces, especially polishes and edge rounding. At the same time, heterogeneous basalts, with prismatic crystals and a very fine-grained groundmass such as BT2 and BT5, do not develop micro-traces as well. BT1 and BTD present similar patterns both in their homogeneous internal structures and in use-wear trace development. Likewise, both BT2 and BT5 also show a similar internal structure and composition, and both behave similarly, with a scarce development of use-wear traces. In the case of BT4, although mineralogically similar to BT1 and BTD, with overall homogeneously sized crystals, traceological results show a pattern closer to BT5. Despite this, there seems to be a relationship between crystal size rough to smooth polish in association with lineal components; $\mathbf{d}$ very bright rough to smooth polish in association with lineal components and rounded areas on the edge

homogeneity and use-wear trace development, which should be further studied in detail.

As for mineralogical composition, results show basalts with feldspar crystals (BT1 and BTD) commonly develop traces better than pyroxene-rich basalts (BT2, BT4, and BT5). This could be due to the difference in hardness between these minerals, with feldspar (hardness of 6.0 to 6.5 on the Mohs scale) being harder than pyroxene (hardness of 5.0 to 6.0 on the Mohs scale). Furthermore, samples with nepheline crystals (hardness of 6.0 on the Mohs scale), such as BT2 and BT5, did not develop traces as well as plagioclase-dominated basalt samples such as BT1 and BTD. This relationship between mineralogical composition and use-wear trace development is inconclusive and most likely interplays with other factors such as the crystal size, but efforts should be made to further investigate this matter.

According to the results obtained for macro-scars, we conclude that the function (use, action, and/or worked material) of flakes cannot be inferred, in contrast with data obtained for 
Fig. 14 Traces after butchering Capra hircus for 33 min with BT4: a semicircular and halfmoon macro-scar morphologies; b micro-scarring formation in association with rough and undulating polish and lineal components; $\mathbf{c}$ bright rough polish with associated lineal components; $\mathbf{d}$ bright rough to undulating polish with associated lineal components

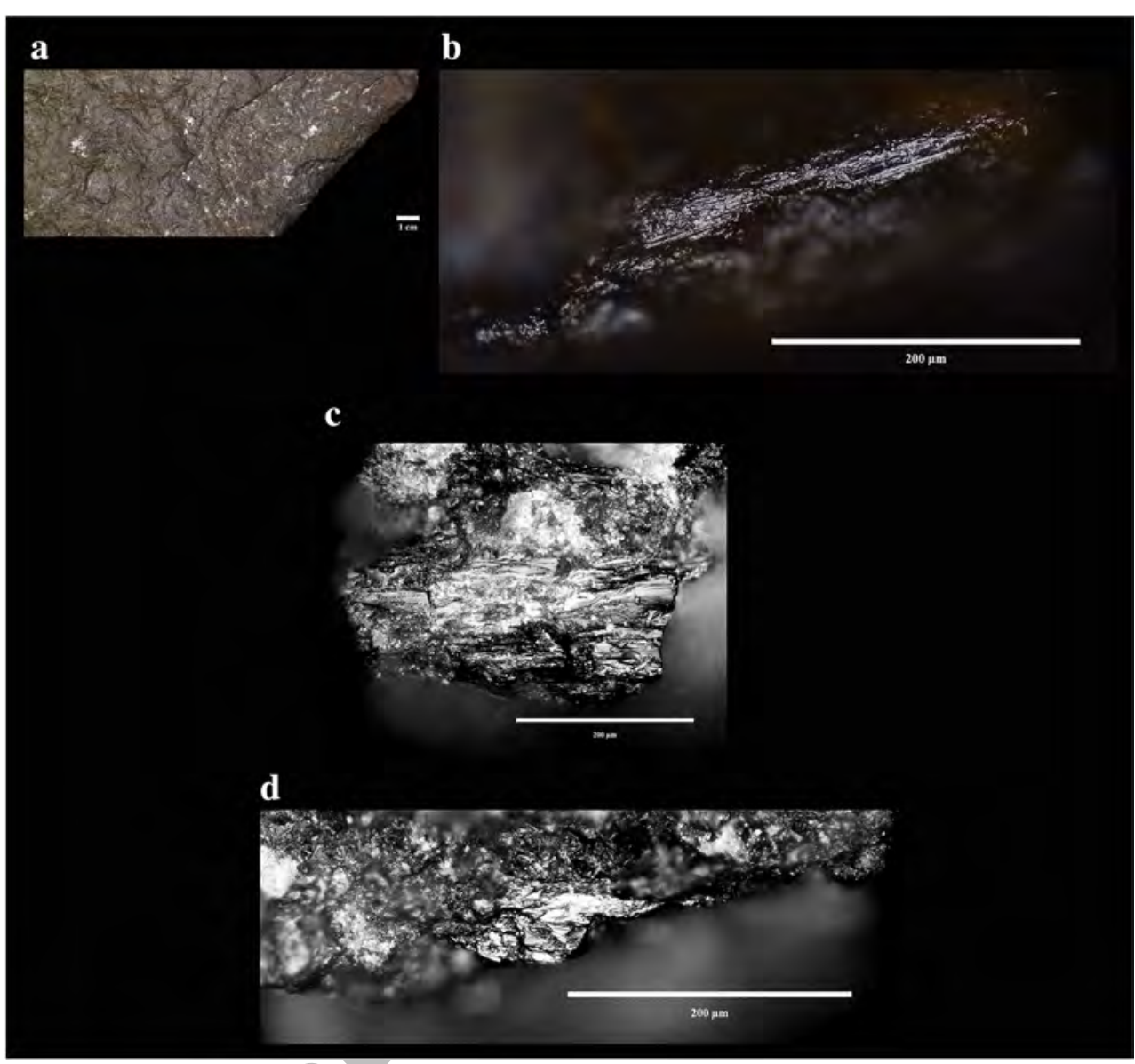

other raw materials (Tringham et al. 1974; Odell and OdellVereecken 1980; Odell 1981; Richards 1988; Grace 1989; Bello-Alonso et al. 2019). The formation of macro-traces along the used edges is scarce and unpredictable, especially for the case of basalt samples with heterogeneous textures (all but BT1). There are even traits that provide some reliable information about function. The location of scars (unifacial or bifacial) seems to be a good indicator of the working movement, helping to distinguish between transversal and longitudinal movements. It is also noteworthy that triangular scars only appear when hard materials are processed with sawing movements (hard wood and bone), and thus they could be a good indicator for this kind of movement and material hardness. Finally, the snap-terminated scars are significantly more abundant in pieces that have processed hard materials (wood and bone), while step terminations are more abundant on pieces that have worked the more resistant USOs (Beta vulgaris and Daucus carota). Hinge terminations appear in association with longitudinal, while transversal movements are more common with vegetal resources (USOs, herbaceous, and wood). Finally, feather terminations are very scarce yet seem to be related with longitudinal activities on vegetable resources (USOs and canes). As in the case study of the experimental basalt collections of Odell and Vereecken (1980), macro use-wear data does not allow for a complete and independent interpretation, playing a more discrete role.

Considering micro use-wear polishes, important differences have been noted among the different basalt samples. In basalts of small and homogeneous-type crystals, none of the polished areas presented a surface area larger than $200 \mu \mathrm{m}$. For this type, of basalt, polishes formed in the areas closest to the used edge and appear with an intermittent distribution along the edge. The best polish formation has been found on basalt flakes characterized by a homogeneous crystal size. The formation of polish on these flakes is more intense, developing more constant polished areas along a greater extension of the edge, however never to the point of creating a completely continuous linked polished area.

Additional observations noted a development of polish with a predominance of rough surface textures in most cases, except for the BT4 basalt when used for butchering activities, which barely developed any polish. The formation of smooth polishes was also noted for flakes used for the processing of the most abrasive worked materials, such as tubers (i.e., Vigna sp.). In order to establish relations between activities and traces, the different brightness of each polish (dull, bright, and very bright) allowed for the differentiation of the type of material being processed. With regard to these data, very 
Fig. 15 Fig. 15A Traces after sawing Bos taurus fresh bone for 30 minutes with BTD: a abundance of snap terminations for macro scars; $\mathbf{b}$ and $\mathbf{c}$ bright rough polish; $\mathbf{d}$ bright rough polish to very bright undulating polish; e very bright undulating polish to smooth polish; Fig. 15B Traces after sawing Bos taurus fresh bone for 30 minutes with BTD: f mate rough polish; $\mathbf{g}$ undulating to smooth polish in association with edge rounding areas; $\mathbf{h}$ smooth polish forming an edge rounding area and; $\mathbf{i}$ rough to undulating polish with microscarring associated

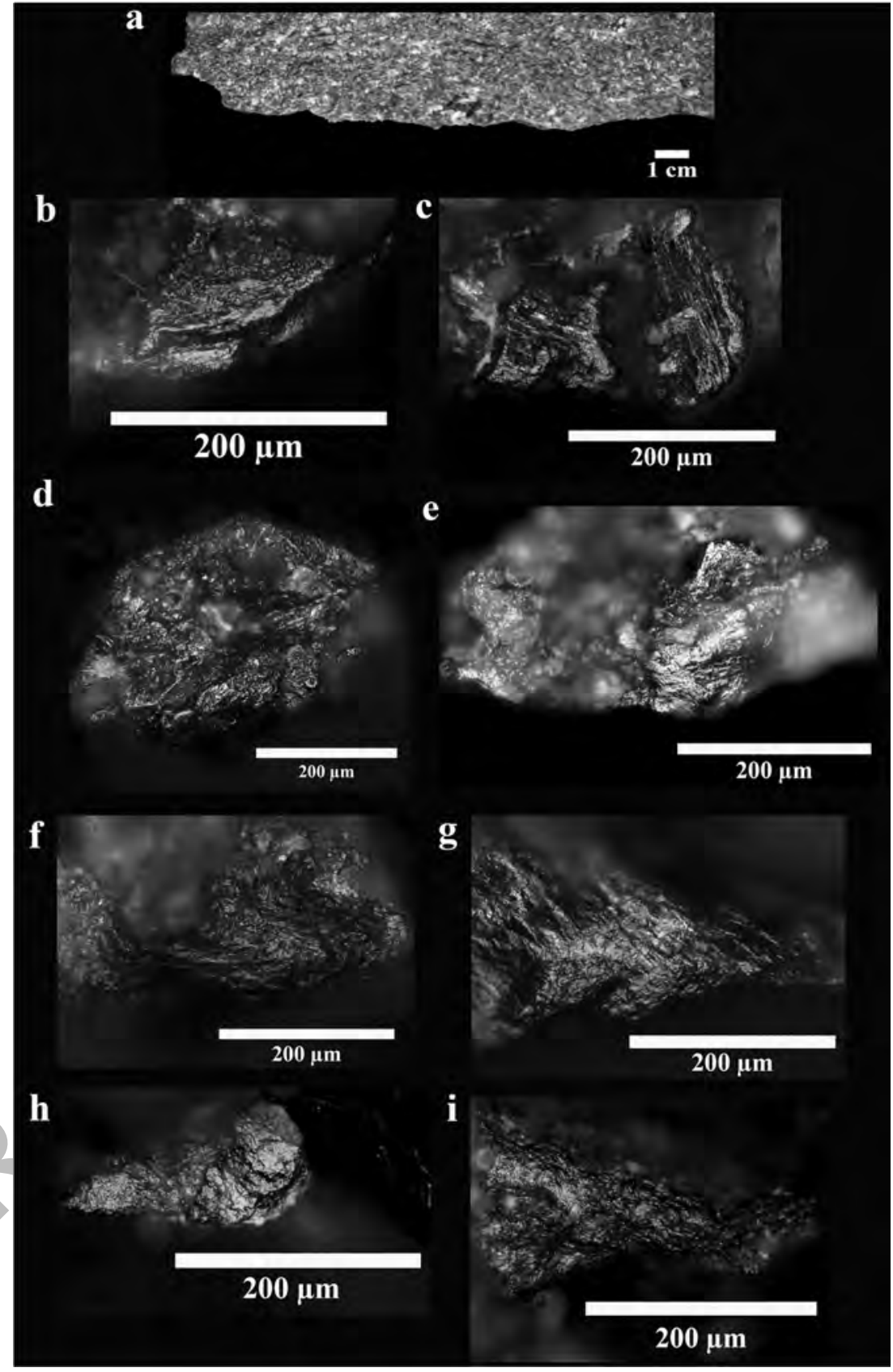

bright polish has been documented to appear in greater percentiles for flakes used to process fresh canes and tubers, except in the case of Beta vulgaris, where peeling was seen to create a dull polish, perhaps as a result of the short working time. In the case of activities performed on bone, a clear development of common dull surfaces was considered notable; only in the case of scraping activities were a few areas with bright reflection detected. Likewise, the polishing itself also presents a trend towards particular orientations, allowing for an approximation towards the directionality of the working movement. Furthermore, data reveals polishes with clear orientation and a greater intensity to be associated more with activities for processing wood and tubers. The peeling experiments, on the other hand, only presented patterns towards transversally oriented movements.

If the data obtained can provide information about the type of material being processed, the development of polishes may also be able to reveal information that can help define functionality in basalt lithic industries. In some flakes, the relationship between polished surfaces and the formation of lineal components have been able to indicate the type of movement during the activity. The formation of this trace is more common in the case of homogeneous basalt flakes, namely, on those 
Fig. 16 Traces after sawing Bos taurus fresh bone for $72 \mathrm{~min}$ with BTD: a semicircular and halfmoon macro-scar morphologies; b bright rough to smooth polish in association with parallel striations; c mate rough polish with bright undulating polish associated with parallel lineal components

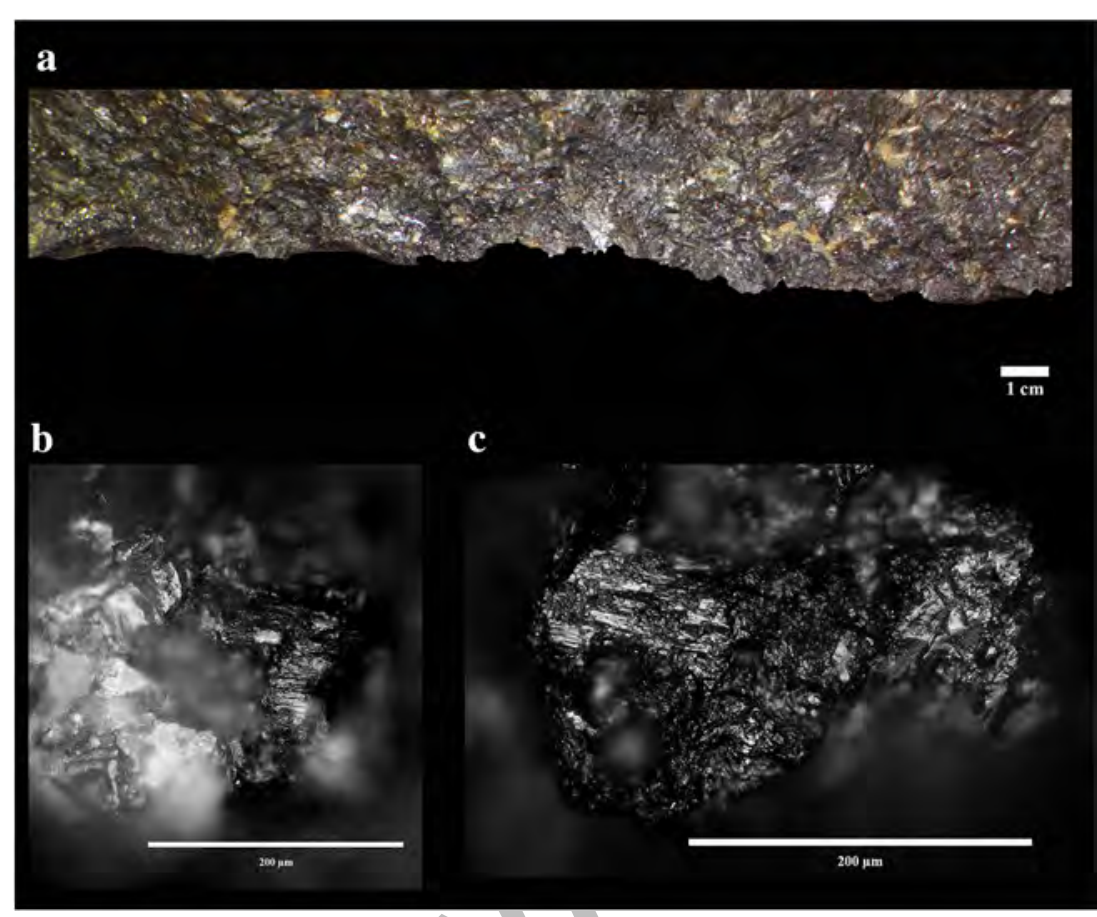

used for longitudinal movements, especially in the case of wood working, bone, and tubers with irregular and resistant peels (Vigna sp. Beta vulgaris, Daucus carota and Zingiber officinale).

On other hand, striations are very rare, appearing mainly on scraping and peeling tools. For transversal activities, we only observed striations on flakes used for the processing of bone and carrot. Likewise, striations are seen to be a common usewear trace on those pieces used for longitudinal and bidirectional movements on irregular or hard materials. The observations indicate that in the processing of hard materials (dry cane sawing, bone sawing, and bone scraping), the number of striations is greater. For dry cane sawing, deeper and longer striations were significant, while for bone activities, short but also deep striations were documented. Nevertheless, these observations could be improved with greater accuracy via precise 3D measurements using confocal microscopy. According to these results, their formation seems to be linked to the processing of abrasive or very hard elements.

Despite showing a pattern almost identical to those developed macroscopically, certain particularities in the location and distribution of scarring were detected microscopically. One of these particularities was the location of micro-scars in transversal processing movements. For scraping and peeling activities, observations for the formation of few and small micro-scarring on the face of the edge are of interest. Likewise, a greater abundance of micro-scars on tools used for the processing of hard materials was also located (i.e., wood, bone, and dry cane). This greater abundance of micro-scars is especially significant in longitudinal activities. Bone scraping is the only exception that maintains the same patterns as bone sawing. In general, micro-scarring abundance, morphology, and distribution can thus be considered a reliable indicator of the hardness of the material being processed and the type of activity being carried out.

Finally, edge rounding is clearly visible under low magnifications. These use-wear traces are commonly observed on all types of basalt used in almost all activities linked to the degree of polish development. According to the data obtained, this study has been able to conclude that, although basalt crystal grain and its degree of homogeneity condition the formation of use-wear traces, edge rounding reaches its highest development when used for the processing of bone. Edge rounding is also well developed on flakes used for the processing of hard wood and the more abrasive tubers with an important development of zones with this type of trace. In general terms, a light to moderate edge rounding development on basalt experimental flakes provided information about the hardness or abrasiveness of the material being processed in combination with the descriptions of polish.

In addition to these observations, this study has also taken into consideration results obtained from other experimental papers looking for similarities and differences in use-wear formation patterns (Plisson 1982 and 1985; Richards 1988). When considering the work of T. Richards (1988) and considering the differences between the basalts, the most significant differences are detected when considering their use of retouched tools. Richards located continuous overlapping and superimposed patches of micro-scars, while our results show a clear tendency for isolated scars without overlapping and superimposed patterns. At the same time, said author's experiments revealed the orientation of micro-scars to be 


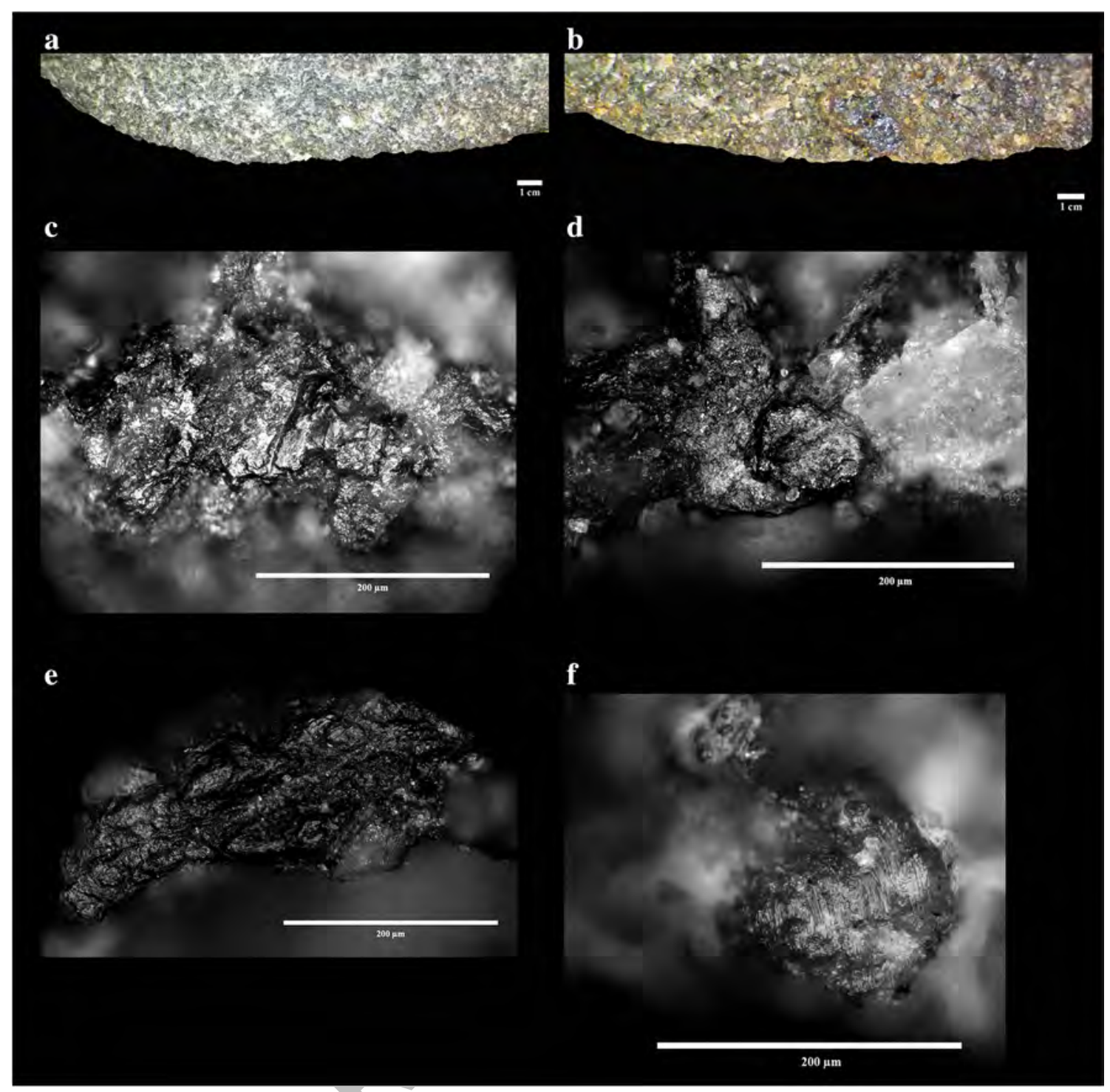

Fig. 17 Traces after scraping Bos taurus fresh bone for 30 min with BTD: a semicircular, half-moon, and few triangular macro-scar morphologies; $\mathbf{b}$ the terminations are on snap and step; $\mathbf{c}$ and $\mathbf{d}$ mate rough polish to very

clearer on flakes used to process bone, while results here argue clear orientations of micro-scarring to be clear only in the case of dry cane sawing activities. Many noticeable differences have also been seen considering the formation of pits, a feature practically absent in all of our experiments. Richards observed abundant pit formation in the pieces used for processing green plants, yet in the basalts with homogeneous crystal sizes used for cutting fresh grass, our results are unable to detect the same patterns, although the typical "corn gloss" polish was indeed observed (Odell 1980; Richards 1988).

The results obtained in this study show the relevance of both experimental protocols and the incorporation of all those analyses that allow for the improvement of the interpretation of use-wear trace formation. In the case of petrological data, the advantages have been remarkable. Their incorporation has bright smooth polish; e mate rough polish to bright undulating polish; f smooth polish formation with oblique striations and edge rounding

undoubtedly made it possible to describe the internal structure of the raw materials and, through this, specify the corresponding technical issues. The combination of petrological and traceological data thus prove the relevance of these experimental protocols as an optimal means of characterizing usewear traces on the same type of rocks. As has been demonstrated in this paper, not only does the type of rock determine the type of use-wear being developed but their internal characteristics should also be considered as an important conditioning factor. This set of experimental data allows for the elaboration of reference collections that can be used to analyze archeological material and can also be considered as a means of establishing new ways of analyzing use-wear traces on basalt tools. In this sense, BTD and BT4 show very disparate results despite having an almost identical internal structure, 
thus requiring an increased sample size for future comparisons.

In general terms, this study performs a dual function. On one hand, we have analyzed the characteristics of the same type of basalts found in the archeological register of TK for the study of archeological lithic materials (Fig. S1b). The results obtained in this study support the feasibility of performing traceological analysis on these types of materials, using a basic description of use-wear location to infer the interpretation of movements, hardness, and materials being processed. On the other hand, a combined interpretation and comparative analysis including BTDs have fulfilled a fundamental goal for the present line of investigation. We consider this achievement as a positive advance that may allow for a more detailed analysis of archeological materials, combined with analysis of the internal components for each raw material. A combined analysis of petrological and traceological data have favored a more comprehensive description on how the internal structure of raw materials may determine microtopographic dynamics in basalt. Data presented here has also been able to detect issues with visu characterization of the same raw material types, advising caution and the need for petrological and chemical analyses as support. Also, considering the results obtained and their respective contributions to the study, we think that it would be beneficial to expand the range of analytical techniques, incorporating the use of confocal laser microscopy for microtopographical analysis of polish. Finally, we hope that this experimental study will be helpful to other researchers of basalt lithic materials that may present the same petrographic characteristics.

\section{Conclusions}

As pointed out in our previous experimental study (BelloAlonso et al. 2019), traceological reference collections are still fundamental for the interpretation of the archeological record (Keeley 1980; Plisson 1982 and Plisson 1985; Knutsson 1988a and 1988b; Richards 1988; Sussman 1988; de la Torre et al. 2013; Lemorini et al. 2014 and 2019; de Francisco 2015; Pedergnana and Ollé 2017; Arroyo and de la Torre 2016, 2018; Arroyo et al. 2016). Moreover, for materials different to flint, which has been historically favored in traceological analysis, it is even more important to develop reference collections if we want to broaden our knowledge about use-wear formation in these "not so common" materials. In the particular case study of the Acheulean site of TK (Olduvai Gorge, Tanzania), the need to establish a strong reference collection with a wide variety of basalt types both local and foreign is particularly relevant in order to discern the different activities that are likely to have been performed in this site. These reference collections can be considered useful not only for the study of other basalt tool assemblages at
Olduvai but also for the study of use-wear formation on basalts in different contexts around the world.

The incorporation of petrological analysis can also be considered a fundamental component for the analysis of how internal structure and mineralogical composition can affect the formation of use-wear traces. Through the experimental use of different types of basalts, we have obtained insights about the role of basalt composition in the formation of use-wear traces, which will be very relevant for future analyses of archeological collections. In this sense, the results obtained with basalts characterized by homogeneously sized crystals show that they better record wear-traces and, consequently, archeological tools made on this kind of basalts will be good candidates for future analysis. This conclusion goes in line with previous studies on basalt (Richards 1988) and quartzite tools (Pedergnana et al. 2017; Bello-Alonso et al. 2019), in which petrographic characterization has been revealed to be necessary for a better comprehension of the physical alterations produced by use. In conclusion with this, it may be safe to say that use-wear forms in direct relation to the activity being produced, the duration of said activity, the worked material, the physical properties of the flakes and their edges, and the petrographic nature of the raw material. This is especially relevant in the case of basalt. These differences sustain the interpretation of the activity and the worked material from the identification of particular features of wear traces (polishes, striations, and edge rounding), and these criteria can be applied to the study of archeological collections in order to interpret the function of basalt tools. Nevertheless, as indicated before, these experimental studies should be continued, expanded, and developed in order to obtain better results. Future experimentation should thus explore petrography in more detail, enlarging the reference collection and combining other microscopic techniques such as, i.e., confocal laser microscopy.

In addition to this, as with the case of Naibor Soit Quartzite (Bello-Alonso et al. 2019; de Francisco 2019), the elaboration of an experimental protocol with basalts is especially relevant in the specific case study of the Early Stone Age (ESA). With this study, we continued the traceological analysis in combination with the technological approaches observed in TK (Santonja et al. 2014, 2018; Rubio-Jara et al. 2017), understanding that both are fields of study closely united for the functional discourse (Panera et al. 2019). For this same reason and paying particular attention to the great technological variety found in these archeological contexts, we also included a wide range of worked materials and movements. Through this and with the objective of obtaining more paleoenvironmental data from Olduvai Gorge sites in the future, we believe that we can get closer to the interpretation of the economic activities carried out by these early hominin populations. 
Acknowledgments We want to thank C. Saínz, A. Álvaro Gallo, and I. Sarró from Centro Nacional de Investigación sobre la Evolución Huamana for their help and the facilities provided to carry out the petrographic study. We wish to express our gratitude to A. San Emeterio, CENIEH Prehistoric Technology and Archaeology Laboratory technique, for the help given in the photographic section and processed from it. At the same time, we thank Lloyd Courtenay for his help with English translation and also to the reviewers for their positive contributions to this work. We also want to take advantage this opportunity to express our sincere gratitude to the Tanzanian assistants, especially Lobelo, Enguiliya, and Lovico, who have always helped us in the butchering activities. Our work was carried out in the framework of The Olduvai Paleoanthropological and Paleoecological Project (TOPPP).

Funding information The Spanish Ministry of Science and Technology provided funding for this research (Projects HAR2013-45246-C3-2-P and HAR2017-82463-C4-2-P).

\section{References}

Álvarez M, Fiore D, Favret E, Guerra RC (2001) The use of lithic artefacts for making rock art engravings: observation and analysis of use-wear traces in experimental tools through optical microscopy and SEM. J Archaeol Sci 28(5):457-464. https://doi.org/10.1006/ jasc. 2000.0571

Arroyo A, de la Torre I (2016) Assessing the function of pounding tools in the Early Stone Age: a microscopic approach to the analysis of percussive artefacts from Beds I and II, Olduvai Gorge (Tanzania). J Archaeol Sci 74:23-34. https://doi.org/10.1016/j.jas.2016.08.003

Arroyo A, de la Torre I (2018) Pounding tools in HWK EE and EF-HR (Olduvai Gorge, Tanzania): percussive activities in the OldowanAcheulean transition. J Hum Evol 120:402-421. https://doi.org/10. 1016/j.jhevol.2017.10.005

Arroyo A, Hirata S, Matsuzawa T, de la Torre I (2016) Nut cracking tools used by captive chimpanzees (Pan troglodytes) and their comparison with Early Stone Age percussive artefacts from Olduvai Gorge. PLoS One 11(11):e0166788

Asryan L, Ollé A, Moloney N (2014) Reality and confusion in the recognition of post-depositional alterations and use-wear: an experimental approach on basalt tools. J :Lithic Stud 1(1):9-32. https:// doi.org/10.2218/jls.v1i1.815

Bello-Alonso P, Rios-Garaizar J, Panera J, Pérez-González A, Rubio-Jara S, Rojas-Mendoza R, Domínguez Rodrigo M, Baquedano E, Santonja M (2019) A use-wear interpretation of the most common raw materials from the Olduvai Gorge: Naibor Soit quartzite. Quat Int(in press). https://doi.org/10.1016/j.quaint.2019.09.025

Benito-Calvo A, Arroyo A, Sánchez-Romero L, Pante M, de La Torre I (2018) Quantifying 3D micro-surface changes on experimental stones used to break bones and their implications for the analysis of Early Stone Age pounding tools. Archaeometry 60(3):419-436. https://doi.org/10.1111/arcm.12325

Clemente, I. \& Gibaja, J.F. (2009). Formation of use-wear traces in nonflint rocks: the case of quartzite and rhyolite. Differences and similarities. In: Non-flint raw material use in prehistory. Old prejudices and new directions. UISPP - Proceedings of the World Congress (Lisbon, 4-9 September 2006), vol 11. B.A.R. International Series Vol. 1939 (Sternke, F., Eigeland, L. \& Costa, L.-J., Eds.), Archaeopress, Oxford: pp. 93-98

Cotterell B, Kamminga J (1979) The mechanics of flaking. In: Hayden B (ed) Lithic use-wear analysis. Academic Press, New York, pp 97-112

de Francisco S (2015) Estudio funvional lítico en la Early Stone Age (ESA) africana: Estado de la cuestión y prospectiva. Estudios de Cuaternario 5:73-85 de Francisco S (2019) El estudio funcional lítico en la Early Stone Age africana, Aplicación analítica, metodológica y experimental en los yacimientos arqueológicos del Lecho II de la Garganta de Olduvai, Tanzania. Universidad de Valladolid, Valladolid

de la Torre I, Mora R (2005) Technological strategies in the lower Pleistocene at Olduvai Beds I \& II. Eraul 112:1-255

de la Torre I, Mora R (2014) The transition to the Acheulean in East Africa: an assessment of paradigms and evidence from Olduvai Gorge (Tanzania). J Archaeol Method Theory 21(4):781-823

de la Torre I, Benito-Calvo A, Arroyo A, Zupancich A, Proffitt T (2013) Experimental protocols for the study of battered stone anvils from Olduvai Gorge (Tanzania). J Archaeol Sci 40(1):313-332. https:// doi.org/10.1016/j.jas.2012.08.007

Deunert B (1995) A fundamental basalt flake analysis. Based on experimentally-produced and used flakes as well as the prehistoric Waikalua material, vol 614. B.A.R. Inernational Series, Tempus Reparatum, Oxford

Díez-Martín F, Yustos PS, Uribelarrea D, Baquedano E, Mark DF, Mabulla A, Fraile C, Duque J, Díaz I, Pérez-González A, Yravedra J, Egeland CP, Organista E, Domínguez-Rodrigo M (2015) The origin of the Acheulean: the 1.7 million-year-old site of FLK west, Olduvai Gorge (Tanzania). Sci Rep 5:17839

Domínguez-Rodrigo M, Serrallonga J, Juan-Trasserras J, Alcala L (2001) Woodworking activities by early humans: a plant residue analysis on Acheulian stone tools from Peninj (Tanzania). J Hum Evol 40: 289-299

Dubreuil L (2004) Long-term trends in Natufian subsistence: a use-wear analysis of ground stone tools. J Archaeol Sci 31:1613-1629. https://doi.org/10.1016/j.jas.2004.04.003

Estévez, J. J. I., \& Urquijo, J. E. G. (1996). From tool use to site function: use-wear analysis in some Final Upper Palaeolithic sites in the Basque country. BAR

Fullagar R (1986) Use-Wear on quartz. In: Ward G (ed) Archaeology at ANZAAS. Australian Institute of Aboriginal Studies, Canberra, pp 191-197

Grace R (1989). Interpreting the function of stone tools: the quantification and computerisation of microwear analysis. BAR International Series 474, Archaeopress, Oxford

Hay R (1976) Geology of the Olduvai Gorge: a study of sedimentation in a semi-arid basin. University of California Press, Berkeley

Kamminga, J. (1978). Journey into the microcosms: a functional analysis of certain classes of prehistoric Australian tools. Ph. D thesis, University of Sidney. Sidney

Kamminga, J. (1979). The nature of use-polish and abrasive smoothing on stone tools. Lithic use-wear analysis $143-157$

Keeley LH (1980) Experimental determination of stone tool uses: a microwear analysis. The University of Chicago Press, Chicago

Keeley LH (1997). Microwear traces on a selected sample of stone artefacts from Koobi Fora. Appendix 7F. In: Isaac GL, Isaac B. (Eds.), Koobi Fora research project. Vol. 5. Plio-Pleistocene Archaeology. Clarendon Press, Oxford, pp. 396-401

Keeley LH, Toth N (1981) Microwear polishes on early stone tools from Koobi Fora, Kenya. Nature 293:464-495

Knutsson K (1988a) Patters of tools use, Scanning Electron Microscopy of Experimental Quartz Tools. AUN, 10. Societas Archaeologica Upsalensis, Uppsala

Knutsson K (1988b) Making and using stone tools, The Analysis of the Middle Neolithic Sites with Flint in Västerbotten, Northern Sweden. AUN, 11. Societas Archaeologica Upsalensis, Uppsala

Leakey, M.D. (1971). Olduvai Gorge. Excavations in Beds I and II, 1960-1963, vol. 3, Cambridge University Press

Lemorini C, Plummer TW, Braun DR, Crittenden AN, Ditchfield PW, Bishop LC, Hertel F, Oliver JS, Marlowe FW, Schoeninger MJ, Potts R (2014) Old stones' song: use-wear experiments and analysis of the Oldowan quartz and quartzite assemblage from Kanjera South 
(Kenia). J Hum Evol 72:10-25. https://doi.org/10.1016/j.jhevol. 2014.03.002

Lemorini C, Bishop LC, Plummer TW, Braun DR, Ditchfield PW, Oliver JS (2019) Old stones' song - second verse: use-wear analysis of rhyolite and fenetized andesite artifacts from the Oldowan lithic industry of Kanjera South, Kenya. Archaeol Anthropol Sci 9(11): 1-26. https://doi.org/10.1007/s12520-019-00800-z

Mansur Franchomme, (M.E.) (1982) Microwear analysis of natural use striations: new clues to the mechanisms of striation formation. Studia Praehistorica Belgica 2:213-234

Mansur Franchomme, M. E (1983). Traces d'utilisation et technologie lithique: exemple de la Patagonie (Doctoral dissertation)

Marlowe FW, Berbesque JC (2009) Tubers as fallback foods and their impact on Hadza hunter-gatherers. Am J Phys Anthropol 140:751758

Márquez B, Baquedano E, Pérez-González A, Arsuaga JL (2016) Microwear analysis of Mousterian quartz tools from the Navalmaíllo Rock Shelter (Pinilla del Valle, Madrid, Spain). Quat Int 424:84-97. https://doi.org/10.1016/j.quaint.2015.08.052

McHenry LJ, de la Torre I (2018) Hominin raw material procurement in the Oldowan-Acheulean transition at Olduvai Gorge. J Hum Evol 120:378-401

Montgomery, P. (1978). Stone artifacts from the Punchaw Lake site (area C): a late prehistoric occupation in Central British Columbia. M.A. thesis, Department of Archaeology, Simon Fraser University, Burnaby

Odell GH (1975) Micro-wear in perspective: a sympathetic response to Lawrence H Keeley. World Archaeol 8(2):226-240

Odell GH (1980) Butchering with stone tools: some experimental results. Lithic Technol 9:39-48

Odell GH (1981) The mechanics of use-breakage of stone tools: some testable hypotheses. J Field Archaeol 8(2):197-209

Odell GH, Odell-Vereecken F (1980) Verifying the reliability of lithic use-wear assessments by 'blind tests': the low-power approach. J Field Archaeol 7(1):87-120

Panera J, Rubio-Jara S, Domínguez-Rodrigo M, Yravedra J, MéndezQuintas E, Pérez-González A, Bello-Alonso P, Moclán A, Baquedano E, Santonja M, (2019) Assessing functionality during the early Acheulean in level TKSF at Thiongo Korongo site (Olduvai Gorge, Tanzania). Quat Int 526:77-98

Pedergnana A, Ollé A (2017) Monitoring and interpreting the use-wear formation process on quartzite flakes through sequential experiments. Quat Int 427:35-65. https://doi.org/10.1016/j.quaint.2016. 01.053

Pedergnana A, García-Antón MD, Ollé A (2017) Structural study of two quartzite varieties from the Utrillas facies formation (Olmos de Atapuerca, Burgos, Spain): from a petrographic characterisation to a functional analysis design. Quat Int 433:163-178. https://doi.org/ 10.1016/j.quaint.2016.02.005

Plisson, H. (1982). Une analyse fonctionnelle des outillages basaltiques. In: Tailler! Pour quoi faire. Recent Progress in Microwear Studies (Cahen, D., Ed.), Musée Royal de l'Afrique Centrale, Tervuren: p. 241-244. (in French) ("A functional analysis of basalt tools")

Plisson H (1985) Etude fonctionnelle d'outillages lithiques préhistoriques par l'analyse des micro-usures: recherche méthodologique et archéologique. Université de Paris I

Pontzer H, Raichlen DA, Wood BM, Mabulla AZ, Racette SB, Marlowe FW (2012) Hunter-gatherer energetics and human obesity. PLoS One 7(7):e40503

Price-Beggerly P (1976) Edge damage on experimentally used scra pers of Hawaiian basalt. Lithic Technol 5(3):22-24

Richards TH (1988) Microwear patterns on experimental basalt tools, B.A.R. International Series Vol. S460. British Archaeological Reports, Oxford, $283 \mathrm{p}$

Rodríguez Rodríguez AC (1998). Primeras experiencias de análisis funcional en los instrumentos de basalto tallado de Canarias. El ejemplo del material prehistórico de la isla de La Palma. Vegueta, 3: 29-46. (in Spanish) ("First experiences of functional analysis of basalt knapped artefacts in Canarias. The example of prehistoric material of La Palma island")

Rubio-Jara S, Panera J, Santonja M, Pérez-González A, Yravedra J, Domínguez-Rodrigo M, Bello P, Rojas R, Mabulla A, Baquedano E (2017) Site function and lithic technology in the Acheulean technocomplex: a case study from Thiongo Korongo (TK), Bed II, Olduvai Gorge, Tanzania. Boreas 46(4):894-917. https://doi.org/10. 1111/bor.12275

Santonja M, Panera J, Rubio-Jara S, Pérez-González A, Uribelarrea D, Domínguez-Rodrigo M, Mabulla AZP, Bunn HT, Baquedano E (2014) Technological strategies and the economy of raw materials in the TK (Thiongo Korongo) lower occupation, Bed II, Olduvai Gorge, Tanzania. Quat Int 322:181-208. https://doi.org/10.1016/j. quaint.2013.10.069

Santonja M, Rubio-Jara S, Panera J, Pérez-González A, Rojas-Mendoza R, Domínguez-Rodrigo M, Mabulla AZP, Baquedano E (2018) Bifacial shaping at the TK Acheulean site (Bed II, Olduvai Gorge, Tanzania): new excavations 50 years after Mary Leakey. In: In The emergence of the Acheulean in East Africa and beyond. Springer, Cham, pp 153-181. https://doi.org/10.1007/978-3-319-75985-2_8

Schnorr SL, Crittenden AN, Venema K, Marlowe FW, Henry AG (2015) Assessing digestibility of Hadza tubers using a dynamic in-vitro model. Am J Phys Anthropol 158(3):371-385

Schutt, J.A. (1982). A comparative analysis of wear patterns on experimental lithic flake tools: the re-examination of current concepts in tool utilization. M.A. thesis, Department of Anthropology, University of New Mexico

Stanfford BD (1977) Burin manufacture and utilization: an experimental study. J Field Archaeol 4:235-246

Stemp WJ, Morozov M, Key AJ (2015) Quantifying lithic microwear with load variation on experimental basalt flakes using LSCM and area-scale fractal complexity (Asfc). Surf Topogr: Metrology and Properties 3(3):034006

Sussman C (1987) Résultats d'une étude des microtraces d'usure sur un échantillon d'artefacts d'Olduvai (Tanzanie). L'Anthropologie 91(2): 375-380

Sussman C (1988) A microscopic analysis of use-wear polish formation on experimental quartz tools. In: British Archaeological Reports International Series, 395th edn. Archaeopress, Oxford

Tringham R, Cooper G, Odell GH, Voytek B, Whitman A (1974) Experimentation in the formation of edge damage: a new approach to lithic analysis. J Archaeol Sci 1:171-196

Ungar PS, Grine FE, Teaford MF (2006) Diet in early Homo: a review of the evidence and a new model of adaptive versatility. Annu Rev Anthropol 35:209-228

Vaughan P (1981) Microwear analysis of experimental flint and obsidian tools. Staringia 6(1):90-91

Yravedra J, Domínguez-Rodrigo M, Santonja M, Rubio-Jara S, Panera J, Pérez-González A, Uribelarrea D, Egeland C, Mabulla AZP, Baquedano E (2016) The larger mammal palimpsest from TK (Thiongo Korongo), Bed II, Olduvai Gorge, Tanzania. Quat Int 417:3-15

Yravedra J, Diez-Martín F, Egeland CP, Maté-González MÁ, Palomeque-González JF, Arriaza MC, Aramendi J, García Vargas E, Estaca-Gómez V, Sánchez P, Fraile C, Duque J, de Francisco Rodríguez S, González-Aguilera D, Uribelarrea D, Mabulla A, Baquedano E, Domínguez-Rodrigo M (2017) FLK West (Lower Bed II, Olduvai Gorge, Tanzania): a new early Acheulean site with evidence for human exploitation of fauna. Boreas 46(4):816-830

Publisher's note Springer Nature remains neutral with regard to jurisdictional claims in published maps and institutional affiliations. 